\title{
The Diffusion of Modern Manufacturing Practices: Evidence from the Retail-Apparel Sectors
}

\author{
Margaret Y. Hwang \\ Harvard University \\ mhwang@fas.harvard.edu \\ David Weil \\ Boston University \\ davweil@bu.edu
}

February 1997

We thank Susan Athey, Richard Caves, John Leahy, and Linus Yamane for advice and useful suggestions and for comments of seminar participant at Harvard University, Boston University, and MIT. We are also grateful to our colleagues Frederick Abernathy, John T. Dunlop, and Janice Hammond at the Harvard Center for Textile and Apparel Research for helpful discussions. This research was made possible by generous support from the Alfred Sloan Foundation, the Harvard Business School, and the National Science Foundation. The opinions and conclusions expressed in this paper are those of the authors. This paper has been screened by the U.S. Bureau of the Census to ensure that no confidential information was disclosed. 


\title{
The Diffusion of Modern Manufacturing Practices: Evidence from the Retail-Apparel Sectors
}

\begin{abstract}
As in many industries, firms in the apparel industry exhibit substantial heterogeneity in the adoption of "modern manufacturing" practices. Based on detailed business-unit level data, we show that this heterogeneity can be explained by differences in product demand composition faced by apparel firms coupled with the existence of complementarities between firm inputs. We show that the interaction between these explanatory factors means that complementarities between inputs may emerge over time rather than all at once as is often assumed in other studies of complementarities.
\end{abstract}

Margaret Hwang

Assistant Professor of Economics

Pomona College

Hahn Building 109

Harvard Avenue

Claremont, CA 91711

email: mhwang@pomona.edu
David Weil

Assistant Professor of Economics

Boston University

School of Management

595 Commonwealth Avenue Room 520A

Boston, MA 02215

$617-353-4615$

Fax: 617-353-6667

email: davweil@bu.edu 
"Manufacturing is undergoing a revolution. The mass production model is being replaced by a vision of a flexible multiproduct firm that emphasizes quality and speedy response to market conditions while utilizing technologically advanced equipment and new forms of organization." - Milgrom and Roberts (1990)

\section{Introduction}

Technological advances in manufacturing enable firms to produce a range of products more rapidly and efficiently. As these changes affect firm organization and market structure, economists have begun to think more carefully about the economics of modern manufacturing. Milgrom and Roberts (1990) present a model to explain the observation that in the 1980s, many manufacturing firms simultaneously adopted a number of new manufacturing practices in the areas of product design, manufacturing, marketing and organization. They argue that this observation can be understood as resulting from two forces. First, falling input prices (such as the price of information technology) increased the returns to some of the modern manufacturing practices. Second, the practices associated with modern manufacturing are mutually complementary, and thus firms which adopt some of the practices will have greater incentives to adopt the remaining complementary practices. These two forces together with the presence of nonconvexities (such as discrete choices about technology adoption) can lead to a situation where small changes in input prices lead a firm to make large changes in their entire manufacturing organization.

If firms in the same industry face the same input prices at each point in time, we would expect to observe firms all making the same adoption decisions. Empirically, however, we observe heterogeneity across firms in the timing of adoption. This is contrary to what some of the literature on complementarities has implied. This inconsistency between existing theory and evidence presents an empirical puzzle which challenges us to find an alternative way of explaining the cross sectional differences in adoption patterns.

In order to explain these cross sectional differences, this paper explores several sources of heterogeneity by using the retail - apparel sectors as an empirical case study and focusing on four specific "modern manufacturing" practices: bar coding, order processing, 
distribution and assembly activities. First, we show that different business units serve different kinds of customers (retailers), and the degree to which these customers engage in what we call "lean retailing" affect the likelihood that the manufacturer adopts complementary modern manufacturing practices.

Second, we posit that subsets of complementary practices may be adopted at a given point in time while the total set of complementary activities may not. In the presence of adjustment costs, and differences in demand, the timing of adoption of mutually complementary practices need not coincide. The lag time may be due to the expectation of higher demand or lower prices. It may be more profitable to wait and hold the option to invest rather than exercising the option right away; complementarities between inputs may not dominate adjustment and/or investment costs in the short run. Thus, firms facing complementarities between choices may indeed change "only a few of the system elements at a time to their optimal values." 1 This suggests that complementary inputs may be adopted sequentially, requiring an analysis of how adoption of some practices in previous periods increase the likelihood of further technology adoption in later periods.

By analyzing detailed business unit-level data on the U.S. apparel industry, our study explores these hypotheses regarding the adoption of modern manufacturing practices. Most firm or establishment level data sets commonly used by economists do not provide the level of detail necessary to test for complementarities. Individual case studies can provide suggestive evidence, but they do not lend themselves to systematic analysis afforded by microdata. Our data set provides detailed business unit information about product tracking, order processing, distribution, and assembly practices, and allows us to explore the adoption process in greater detail. Further, in contrast to many other studies of complementarities, our empirical approach is motivated by an explicit model of the sequence in which complementary inputs are adopted. ${ }^{2}$

\footnotetext{
1 Milgrom and Roberts (1995) p.191.

2 See Athey and Stern (1996) for further discussion of the existing empirical literature.
} 
Section II discusses the emergence of new methods of retailing and describes how these product market forces may raise the returns of investments in a set of potentially complementary manufacturing practices. Section III presents empirical evidence on patterns of adoption of advanced manufacturing practices in the industry, and tests for the existence of complementarities between these practices using adoption- and performance-based approaches. Section IV analyzes adoption decisions in a dynamic context, and presents more robust evidence of complementarities over time. Implications and concluding remarks are presented in Section V. Appendices I and II provide detailed descriptions of the data employed in the analysis.

\section{Product Market Change and the Adoption of Modern Manufacturing Practices}

Despite its reputation as a low-skill, sunset industry, U.S. apparel business units have adopted a wide variety of information, distribution, and manufacturing practices usually associated with more "advanced" firms and industries. These practices involve applications of technologies that increase the speed and accuracy of information flow between and within firms, reduce the costs of using point of sales and order information, and increase the ability of firms to manufacture a growing diversity of products in a flexible manner. As a result, an increasing percentage of apparel business units are using sets of practices often associated with "lean production" (Womack, Jones, and Roos 1991), "flexible manufacturing" (Piore and Sabel 1984), or "modern manufacturing" (Milgrom \& Roberts 1990).

The adoption of advanced manufacturing practices by apparel business units occurs in the context of change in the basic relationship between apparel suppliers and their retail customers. Retail practice is being transformed by the incorporation of information processing technologies, major investments in automated distribution centers, and the creation of new pricing, inventory, and logistic strategies which draw on these investments. Innovative retailers who have made these investments attempt to reduce their exposure to demand risk by adjusting the supply of products at retail outlets to match consumer demand on the basis of daily, point of 
sale information flowing from barcode scanners within individual stores. These retailers consolidate this data and use it to generate orders from suppliers based on actual sales. As a result, they require that suppliers compete not only on the basis of price, but on their ability to meet "rapid replenishment" requirements (i.e. a reduced amount of time from receipt of the retail order to arrival of the ordered goods at the retail distribution center), and provide associated services required to move supplier shipments rapidly through retail distribution centers and to individual stores for stocking.

This section begins with a description of traditional and emerging methods of retailing because of their importance to the choice of manufacturing practices. It then discusses four "modern manufacturing" practices that form the empirical basis of this article and describes their interaction with one another and with changes in the retail product market. This provides the basis for analyses of complementarities that follow in Sections III and IV.

\section{Changes in the Product Market: Traditional versus Lean Retailing}

Retailing is the link between the final consumer and the apparel / textile manufacturing system. Retail strategy and organizational design therefore affects both the historic organization of apparel manufacturing, as well as the benefits and costs of adopting modern manufacturing practices within these firms.

The typical number of individual products (typically measured in "stock keeping units" or SKUs ${ }^{3}$ ) provided by retailers over the course of a year can range from 10,000 for a price club food store offering a limited number of products sold in large quantities, to an upscale department store which may stock over 1 million different items. Retailers face an ongoing problem of managing this profusion of products. At an operational level, this means deciding what types and how many of any one good it should stock in order to maximize its profits per square foot of available space. This requires allocating space to different goods efficiently, responding to shifts in consumer tastes, setting pricing policies (markup and markdowns) to

\footnotetext{
3 A stock-keeping unit is the most detailed level of product specification; for apparel products a SKU is a unique product with a specified manufacturer, color, fabric, style, and size. An example of a SKU is a white, pin-point oxford cloth, men's button-down dress shirt, size 16" (collar) - 35" (sleeve) manufactured by a specific company.
} 
deal with both the direct cost of goods and the uncertain nature of consumer demand, and controlling inventories to reduce direct and indirect costs of holding goods.

Traditional retailers provided diverse goods at competitive prices to customers by ordering desired products far in advance of the selling season. Retail buyers, assigned to a specific product line area, would procure products based on their assessment of what would sell and using information (or best guesses) on the distribution of sizes and variety of products based on passed experience or rules of thumb. These transactions might occur between 18 and 24 months before the goods would ultimately appear on the retailers' selling floor. The critical dimensions of the buyer's activities therefore turned on his or her ability to make accurate predictions of what people would want to buy, and their ability to procure those products at the lowest cost possible.

While the order would specify a delivery time far closer to the sales season, once an agreement had been made between the buyer and the apparel manufacturer, the order would remain unchanged until delivery to the retailers distribution center or individual stores. The typical shipment between an apparel manufacturer and retail customers was large and of low frequency (e.g. once per season). Once delivered, the retailer would hold the products in central warehouses or in inventory at the store site. When the desired time of sale arrived, the product was stocked on the selling floor, and replenished from store- and warehouseinventories as the selling period progressed. Inventory control consisted of bi-annual inventories relying on sales records (receipts) and manual counts of floor-, store- and centralinventory. Overstocks at the close of a season were then marked down for clearance, warehoused in inventory for future sales, or sold to a secondary market supplying discount retailers.

Traditional retailers lowered their direct costs of procurement and in the process usurped the role of wholesalers in the apparel distribution channel (Chandler 1977). Purchasing in large quantities for their stores, however, subjected retailers to the risk attendant with selling "perishable" products like apparel (Pashigian 1988). Retailer pre-commitments meant that new 
information could not be used to modify orders. In terms of retail bottom line, this risk manifested itself in the indirect costs associated with holding inventories of unwanted products or of running out of highly successful hits.

Access to information has become critical to retail success in the 1990s. The ability to gather, transmit, and use information on sales at the cash register has created a new way of offering products to customers: the lean retailer (Abernathy et. al. 1995). The principle of lean retailing is to provide customers a variety of products while reducing exposure to market demand risk by constantly adjusting the supply of products offered to consumers at retail outlets to match actual levels of market demand. Lean retailers attempt to incorporate into their total cost functions both direct product costs (as reflected in the wholesale prices charged by suppliers) and the indirect costs associated with demand uncertainty, including stock-out costs, costs of mark-downs and write-offs, and inventory-carrying costs.

Given the number of SKUs carried by retailers and the enormity of daily transactions, manually capturing this information on a timely basis is very costly. The problem of information acquisition, storage, and transmission instead awaited the fall in price of several key technologies: (1) Bar codes, bar-code scanning equipment, and related technologies that allow rapid, automatic identification of products and packages, (2) electronic information transfers, (3) computer memory and the expansion of computing capabilities through the use of personal and network systems, and (4) automated distribution operations drawing on scanners for automated identification, and computer-controlled conveyance and sorting systems.

Lean retailing involves combining these technologies in order to sell products based on current demand information while minimizing inventories at both the store level (except what is on the sales floor) and firm level (beyond what is moving through distribution centers or awaiting store delivery in anticipation of a distinctive season). These key technologies are used by lean retailers to track sales on an individual style, color (fabric), and size basis at a storelevel on a real-time basis. Based on daily sales information, products are replenished at the 
store level in relatively short basis, drawing on the logistic support for these store deliveries by means of centralized distribution centers.

By using daily demand information arising from point-of-sale data collected at the store-level to govern supply, lean retailers change the flow of information and goods with apparel suppliers. Most importantly, rather than infrequent, large batch orders, order flows become more continuous, and of lower volume (but oftentimes greater diversity). These orders are placed close to the time that the retailer seeks delivery of the product.

Table 1 presents data on delivery requirements faced by apparel suppliers in 1988 and 1992, overall and within specific retail channels. Retailing practices remained characterized by the traditional model described above in 1988. Table 1a and $1 \mathrm{~b}$ portray the large share of products shipped on an infrequent or non-replenishment basis in 1988. For example, 69\% of mass merchant (e.g. Kmart and Wal-Mart) shipments were purchased on a single order basis, as were $56 \%$ of national chain(e.g. Sears and JC Penney) and $61 \%$ of department store sales (e.g. Dillards, Federated, Nordstrom). In contrast, less than $10 \%$ of sales were replenished on a daily or weekly basis for any of these categories.

Replenishment demand increased markedly in the four years following 1988. Mass merchants which typically provide apparel at low price points increased the percent of sales replenished on a daily or weekly basis six fold from $7 \%$ to $42 \%$. National chains which provide apparel at medium price points increased the percent of sales replenished on a daily or weekly basis more than five fold from $8 \%$ to $42 \%$. Department stores which typically provide the widest variety of apparel and sell at the highest price points also increased the percent of sales replenished on a daily or weekly basis increased (from 2 to $27 \%)^{4}$. Table $1 \mathrm{~d}$ shows that the percent of total sales replenished on a daily or weekly basis grew from $9 \%$ to $34 \%$, while the percent of sales never replenished on a less than monthly basis fell by two thirds from $62 \%$ to $23 \%$.

\section{Manufacturing Responses: Four Technologies}

\footnotetext{
${ }^{4}$ See Abernathy et al (1995) for more details about the various channels of distribution.
} 
Four specific advanced manufacturing practices are related to apparel suppliers' ability to provide products under the emerging system of retailing. These practices represent a combination of technological innovations and business practices that affect how apparel suppliers acquire and use information concerning demand at the product level. Three of these practices are generic to a wide variety of consumer product industries while the fourth has parallels in many manufacturing settings that draw on various methods of team production.

The first practice area involves the adoption of standardized product identification systems (called the Uniform Product Code or UPC) which provide unique, electronically scannable, identifiers (barcodes) for classifying products at the detailed stock keeping unit (SKU) level. The availability of a standardized system of classification and the means to inexpensively input, store, transmit, and access information on demand opens up a wide variety of opportunities for barcode adopters. Use of the UPC barcode system (BARCODE) confers to adopters a potential capability of significantly decreasing transaction costs along a variety of parameters. While BARCODE is measured as a specific practice, it implies the adoption of a number of technological investments by business units (bar-code readers and writers, hand scanners, computer hardware and software) and conventions (the uniform system of barcodes promulgated by the Uniform Product Council).

The second practice area involves the use of electronic data interchange (EDI) as a means of transmitting data on orders between apparel suppliers and retailers. Like barcodes, the use of EDI requires a set of investments by suppliers and customers (computer hardware and software capable of sending and receiving data rapidly) and conventions (a standardized system of data interchange for transmission). We use the percentage of purchase orders received via EDI as the measure of adoption of this suite of activities.

The third practice area involves changes in the way business units prepare products for shipment. Modern distribution centers of major retailers are capable of rapidly identifying and sorting incoming shipments from suppliers like the apparel business units in our sample through the use of scanning systems, automated sortation and conveyers, and computer controls. At the 
same time, these systems use this information to process and reconcile invoice information on incoming and outgoing shipments. This requires that incoming shipments adhere to a set of technological and process standards regarding the use of barcode systems for labeling boxes, and the parallel adoption of standards for packing, placement, and shipping of products. We measure this practice area as the percentage of shipments sent by business units with a barcoded marker (AUTODIST).

Finally, there are innovations in the assembly stage of apparel production, via "modular" (or team) production. Rather than breaking up assembly (sewing) into a long series of small steps, modular production entails grouping tasks and assigning those tasks to a module (team) as a means of reducing the elapsed throughput time required to assemble a given product. Adoption of this assembly technique entails altering the physical layout of sewing machines, and changes in human resource systems including training requirements, compensations systems, and methods of supervision (Dunlop and Weil 1996). The use of this set of practices is measured by the percentage of domestically produced sewing output produced using modular or related team assembly systems (TEAM).

Firms responding to frequent purchase order requests from retailers benefit from the combination of these practices. The access to timely, accurate, and low-cost information via UPC barcoding and EDI transmission reinforce the benefits conferred by providing retailers with shipments marked with barcodes that adhere to common shipping standards. Business units which adopt both barcodes and EDI are able to reduce the transaction costs for processing each shipment since the combination enables retailers to scan incoming shipments, check them against purchase orders, and authorize payments to suppliers as well as rapidly identify discrepancies between invoices and actual shipments. Furthermore, when these two practices are adopted in the presence of shipping container markers and related shipping conventions (e.g. placement of barcodes on containers; hand scanning individual products as they are loaded into a box in order to generate a barcoded shipping container marker), the individual benefit of each practice is further enhanced as order processing occurs more rapidly, accurately, and with 
less paper. The returns to using a uniform system of product identification thus grow with the presence of systems to transmit information on a more frequent basis at lower cost per transmission. In turn, the returns to a uniform "platform" of electronic transmission systems rise with a uniform system of product classification which enables information to be transmitted more efficiently. These gains are further reinforced by the secular fall in the cost of computer hardware and memory.

Modular production enables firms to reduce the time required for a given product to move through the assembly process. By substantially reducing work-in-process buffers in assembly, throughput time on modular lines among the sample's business units is 2 vs 9 days for standard methods of assembly. The benefits of throughput reduction cannot be fully realized, however, if firms are not rewarded for their ability to replenish rapidly. Rapid replenishment, in turn, is premised on the availability of detailed demand data (BARCODE) and its frequent and accurate transmission (EDI). In this way, modular assembly systems are expected to be complementary with advanced information practices. Advanced practices in distribution (AUTODIST) and team production may also be complementary because of their mutually reinforcing impacts on reducing throughput time. Throughput time reduction can be lost if the distribution method is non-innovative, or if there are other impediments to the movement of products from the apparel business unit to the retailer. Alternatively, distribution operations that efficiently process finished products (i.e. do not hold them in warehouses or inventories) reinforce the benefits of a modular assembly system.

In sum, each innovation itself comprises a distinctive bundle of practices. It is important to note that adoption decisions regarding the four practices are typically made by managers in different departments of apparel business units. Barcodes and UPC decisions primarily reside in the marketing / merchandising area because of their relation to both product specification and pricing. Decisions regarding EDI and related systems reside with Management Information System departments. AUTODIST systems are the domain of logistic or distribution departments. Finally, decisions regarding apparel assembly (as in TEAM) 
typically reside with manufacturing managers as well as human resource personnel because of the compensation / training implications of such systems. The four "bundles of practices" are thus sufficiently independent from one another to make complementarity an open question.

\section{Adoption and Diffusion of Advanced Manufacturing Practices}

Section II provided a possible explanation for the adoption of the four manufacturing practices based on shifts in product demand coupled with underlying complementarities of practices. This section explores this explanation in a more formal framework. The first section examines patterns of adoption of the four manufacturing practices at two points in time: 1988 and 1992. We then look explicitly at the relation of adoption of practices to changes in apparel business units' composition of retail demand. The next sections subject the data to a number of tests used to test for complementarities, accounting in part for the changing impact of retail demand on the existence and "strength" (defined below) of those complementarities.

\section{Patterns of Adoption}

There has been a substantial increase in the use of a variety of modern manufacturing practices in apparel over the study period. Some business units have adopted a wide range of such practices while others have adopted few if any. For each manufacturing practice, table 2a indicates the percentage of business units in the sample that use the practice to any extent. Complementarities should affect both the decision to use a practice and the decision about the extent to which these practices should be used. Adoption is defined as equal to one if some positive amount of the technology is utilized by the business unit. Diffusion values range from $0-100 \%$ and are measured by the continuous variables, BARCODE, EDI, AUTODIST, and TEAM. Hence in table $2 b$, we report the average percent of sales affected by each practice. Table $2 \mathrm{c}$ provides the average percent sales affected by each practice conditional on adoption of that practice. 
In 1988, few business units used computerized systems to capture information for purposes of distribution, utilized automated distribution systems or drew on team ("modular") assembly in apparel production. By 1992, the incidence of these practices had increased markedly. In table 2a, we see that the percent of firms using Uniform Product Codes (a standardized system of product identification) rose from $54 \%$ to $75 \%$ in four years, while the percent firms adopting EDI and modular assembly more than doubled in four years. In table $2 b$, we can see that information system-related practices show dramatic increases in degree of adoption: the average \%sales involving BARCODE more than doubled, while the percent sales involving EDI and AUTODIST grew six fold and four fold, respectively. From table 2c, we show that not only did more apparel firms use advanced manufacturing practices, but those that did adopt them used them for a far greater percentage of their operations. Table 2 demonstrates the extent to which the apparel industry adopted particular innovative practices.

Table 3 presents the joint frequency distributions of these various practices in 1988 and 1992. In 1988, barcoding and order processing practices were not very interrelated: only $25 \%$ of business units had adopted both, while $47 \%$ had adopted neither. By 1992, however, $75 \%$ of the business units had adopted both BARCODE and EDI technologies, while only $8 \%$ had adopted neither. In 1988, 50\% of the firms had adopted neither barcodes or shipping container markers and only 14\% had adopted both. By 1992, half of the firms had adopted both while only $11 \%$ still had adopted neither. Similarly, in 1988, $61 \%$ of the firms had adopted neither EDI or shipping container markers, and only $13 \%$ had adopted both, while in 1992, over half had adopted both while only $14 \%$ had adopted neither. Over time, more firms adopted practices together rather than individually. This could possibly be explained by the fact that the returns to mutual adoption have risen over time.

Table 4 presents a series of conditional probability tables that relate the presence or absence of one innovative practice with another. Firms that adopted BARCODE in 1992 are 50\% more likely to adopt EDI in 1992 than those that had not adopted, and twice as likely to adopt AUTODIST. Firms that adopt EDI are about three times more likely to adopt AUTODIST 
than firms that did not. The probability of TEAM adoption is not significantly affected by the contemporaneous adoption of BARCODE and EDI, although the probability of TEAM adoption is somewhat higher for firms that have adopted AUTODIST than for those that have not. This table implies that there are several close pairwise relationships between the four technology choices that we have chosen to study, namely between BARCODE, EDI, and AUTODIST. It also indicates that the adoption of TEAM is not related to contemporaneous adoption choices of the other technologies.

\section{Retail demand and adoption of modern manufacturing technology}

A supplier facing a growing number of lean retailing customers faces a dynamic investment problem under uncertainty. There is uncertainty regarding the future decline in input prices and the future rise in demand. The firm must weigh the returns from entering into a lean retailing relationship against the investment and adjustment costs. There are two possible adjustment costs. One type of adjustment cost arises from changing existing manufacturing practices. These adjustments costs are relatively high since they are linked to a set of complementary practices arising from historical relations with traditional retailers. Given the high degree of complementarity (internal consistency) in the traditional system, it can be costly to change aspects of production in an incremental fashion.

For example, reducing throughput times in the assembly room requires eliminating a significant percentage of work in process inventories. This cannot easily be done without altering assembly flows within the system, which in turn requires shifts in compensation, skill requirements, and the nature of worker interrelationships (Dunlop and Weil 1996). These adjustment costs may or may not be the same across firms depending on their initial positions. The second type of adjustment cost comes from the loss of the option value of waiting to invest.

If each retailer has preference for a different set of supply practices, then the demand that suppliers face would be idiosyncratic across firms. Since the opportunity cost of investing is a function of this demand, the adjustment cost arising from this source would vary across 
firms. As a consequence, the timing of adoption could vary across firms ${ }^{5}$. Firms which replenish a higher percentage of their products on a more frequent basis may adopt more technologies than do firms which replenish less frequently. Thus, in periods of transition of market practices, divergent production strategies among firms supplying retailers are likely to emerge. Some firms may choose to meet retailer requirements by holding buffer stocks while other firms may meet the same requirements by investing heavily in flexible planning and production practices. In the short term, both types of firms could meet lean retailing requirements, yet diverge considerably in terms of their own internal practices and performance. We expect internal performance measures of these two types of firms to differ systematically on the basis of the chosen strategy.

As a result of the benefit and cost structure underlying adoption, adjustment to lean retailing tends to occur in distinctive "clusters" of practices, adopted as the benefits arising from their use outweigh the adjustment costs of staying with practices from the older system. The extent to which an apparel supplier chooses to invest in activities necessary to supply lean retailers will increase as the percentage of lean retailers in its customer base grows. These differences across business units in expected benefits from investing in modern practices can explain a great deal of the pattern of heterogeneity across firms in adoption patterns.

Milgrom and Roberts (1990) argue that "computerized order processing and a fast means of delivery are complementary to a quick responsiveness of the modern factory to new orders $^{6}$." The demand for quick responsiveness by retailers at the plant level will potentially raise the probability of adoption of the four manufacturing practices, both individually and collectively. We use a direct measure of replenishment demand based on replenishment requirements presented in Table 1: the percentage of sales provided by apparel business units to mass merchants and national chain stores on a daily or weekly basis ("RapidReplen"). We focus on this variable because advanced retailing methods associated with these practices

\footnotetext{
5 See Hwang (1997) for more details

6 Milgrom and Roberts (1990), p.514.
} 
emerged and remain concentrated in these two retail segments. Moreover, daily and weekly orders represent a major change in delivery requirements from those observed at earlier points in the dataset. Figure 1 depicts this dramatic shift in the exogenous parameter, RapidReplen, which has a far higher mean and greater variance in 1992 than it did in 1988.

RapidReplen can be considered exogenous to adoption decisions because it reflects requirements placed on apparel business units by retail customers. The requirements are increasingly considered a precondition of transaction. In the short run, these requirements do not reflect the manufacturers' capabilities to replenish on a daily or weekly basis. Before it is profitable for suppliers to adopt new manufacturing practices, retailers must first make the necessary investments in information technology hardware and software. Retailers come "in front" of the manufacturing changes described above because they control the technology which captures actual consumer demand. Only once retailers use this information to streamline relations with their suppliers can manufacturing firms begin to change internal practices to improve their own performance.

Furthermore, while apparel suppliers may face a changing composition of demand in terms of retail channels in the long run, our sample includes a period of time (1988 to 1992) in which the composition of demand by retail channel remained relatively constant. As the table below indicates, the average change in the percent of sales going through mass merchants and department stores was slightly positive while the percent of sales going through national chain stores and specialty stores was slightly negative. If the composition of demand is relatively fixed in the short run (although adjustable in the long run), RapidReplen can be considered a useful instrument with which to explain adoption.

\begin{tabular}{|c|c|c|}
\hline Channel of Distribution & average change & std deviation \\
\hline mass merchants & $1.9 \%$ & 24.3 \\
\hline national chains & $-3.7 \%$ & 22.1 \\
\hline department stores & $4.5 \%$ & 20.2 \\
\hline specialty stores & $-3.0 \%$ & 19.1
\end{tabular}




\begin{tabular}{|c|c|c|}
\hline direct mailings & $0.3 \%$ & 9.6 \\
\hline
\end{tabular}

Table 5 relates lean retailing to business unit adoption of activities and clusters, comparing adoption rates of various technologies for business units facing low (below median) versus high (above median) replenishment intensity in both 1988 and 1992. Replenishment intensity, RapidReplen88, is measured as the percentage of sales delivered to mass merchant and national chain retailers on a daily or weekly basis based on 1988 levels. In 1988, the frequency of adoption of advanced manufacturing practices is significantly higher only in the case of BARCODE for those facing significant replenishment pressure. In contrast, by 1992, adoption rate of firms experiencing high replenishment intensity is significantly higher than that of firms experiencing low replenishment intensity for all four technologies, suggesting a strong link between rapid replenishment and technology choices. For example, $81 \%$ of the firms adopt BARCODE in 1992 when they experience low RapidReplen while 91\% of the firms adopt if they are under high RapidReplen. And 34\% of firms adopt Modular or TEAM assembly when they experience low RapidReplen while 51\% adopt if they experience high RapidReplen.

The impact of replenishment intensity can be tested more formally by modeling the determinants of the adoption and diffusion of the four technologies. This is done in table 6 which estimates logit regression models of firm technology adoption. In addition to modeling adoption as a function of RapidReplen, several control variables are included. Business unit size (as measured in log sales in 1992) is included since larger firms are able to spread high fixed costs across more output and thus reduce per unit costs. The probability that larger business units invest in these technologies is thus expected to be higher. Furthermore, size is typically found to be a positive determinant of adoption in other studies of technology adoption. The type of products provided by a business unit can also be used to explain adoption. "Basic" type products are the focus of most replenishment programs. Examples of "basic" products include t-shirts, underwear, socks. The percentage of basic products in a business unit's collection should therefore also be related to the incentive to adopt each of the technologies. 
In addition to these common determinants, Table 6 includes five specific control variables. These control variables can be thought of as exogenous factors which only affect practice-specific returns. By including these unique control variables in our adoption models, we hope to account for potential sources of selection bias. ${ }^{7}$ The use of non-proprietary barcode systems is used as a unique control for the adoption of standardized barcodes, since the positive network externalities associated with use of a common (rather than proprietary) bar-code system potentially increases the benefit received from investment in providing barcodes to retail customers. The receipt of detailed point-of-sale data is used as a unique determinant of EDI adoption and degree of adoption, since the benefits of EDI should grow with the volume and detail of information sent via those systems. The ability to provide Advanced Shipping Notices (ASNs) relies on similar technologies as required by marking containers with barcodes, but confers further competitive returns to business units providing this service and is therefore used as a control variable unique to the adoption of AUTODIST. Finally, we use both direct labor costs, LABOR, measured as the average cost per garment or \$/unit associated with assembly of a typical product, and the involvement of manufacturing personnel in initiating rapid replenishment programs (PARTICIP) as control variables for the degree of adoption of modular systems. LABOR is expected to be negatively associated with the adoption of TEAM assembly because it is commonly believed to raise unit labor costs (George 1996). PARTICIP is expected to be positively associated with adoption and degree of adoption of TEAM assembly since participants are more likely to understand the importance of adapting the production process.

In table 6a, we estimate logit models of the adoption of these four innovative practices. We find that replenishment intensity has a significant positive impact on the adoption decision about BARCODE and AUTODIST, but not on EDI or TEAM. In table 6b, we calculate the change in the probability of adoption for a one standard deviation change in the explanatory

\footnotetext{
7 Since they prove to be useful sources of exogenous variation in tables 6, they are used in subsequent empirical tests as instrumental variables.
} 
variable, evaluating the probabilities at the average values of the explanatory variables. For example, firms that are one standard deviation above the mean replenishment demand have a $5.7 \%$ higher probability of adoption of BARCODE than do firms with only $29 \%$ of their sales replenished on this basis, and they have a 3.6\%, $11.3 \%$, and $5.15 \%$ higher probability of adopting EDI, AUTODIST, and TEAM, respectively than do firms with only average replenishment demand. ${ }^{8}$ Table 6 therefore implies that firms under greater replenishment intensity will both be more likely to adopt BARCODE as well as adopt it to a greater extent than firms under low replenishment pressure. Firms under greater replenishment intensity will also be more likely to adopt AUTODIST, but it will not affect their choice about how much AUTODIST to adopt. In contrast, the probability of EDI adoption is not significantly affected by replenishment intensity, but the intensity of usage conditional on adoption is positively affected.

\section{Complementarities among Practices: Adoption Approach}

Several approaches to testing for complementarities have been taken in the empirical literature. Athey and Stern (1996) provide a critical evaluation of these common tests and classify them into two groups: adoption tests and productivity tests. The adoption approach tests for simultaneous adoption of complementary inputs and is examined first. The productivity approach (used in the next section) tests whether firms which have adopted several practices together perform better than do firms which have adopted no or only one practice.

Adoption tests for complementarities often rely on the assumption that the timing of adoption of the potentially complementary inputs occurs simultaneously. A basic test for complementarities involves measuring the degree of correlation between the various technology choices at a point in time. When inputs are complementary, we expect them to be positively correlated. If A and B are complements, more of activity A should be related to more of activity

\footnotetext{
8 Logit regressions were also run on the degree of adoption (percentage of volume where the technology is used). We find that the degree of adoption of BARCODE and EDI is also affected by replenishment intensity. These results are available from the authors.
} 
B. Holmstrom and Milgrom (1994) argue that complementarity is a force which favors positive covariation between the inputs since a change in an exogenous variable which affects one choice will lead a firm to increase all its other technology choices. ${ }^{9}$

Table 7 applies such a static test of adoption to the apparel data. We test the null hypothesis that the unconditional correlations between each pair of choices are zero. Table 7 reports the correlations between intensity of adoption in 1988 and 1992, respectively. The pairwise correlations in 1992 are larger than in 1988 which implies that the benefits of mutual adoption rose between 1988 and 1992 and that adoption choices are more interrelated in 1992.

The increase in significant correlations in modern manufacturing practices between 1988 and 1992 tracks the growth of rapid replenishment demand over the time period. This association may not be coincidental. In 1988, many firms faced virtually no rapid replenishment demand (see Figure 1). By 1992, many firms experienced moderate to high degrees of rapid replenishment demand. There are two possible reasons that the degree of pairwise correlation (and therefore the "strength" of complementarities) rise with replenishment demand over time.

First, as a larger share of sales is made on a frequent replenishment basis, the aggregation of lean retailing customer demand becomes more informative. This allows apparel manufacturing firms to obtain more accurate information about that state of consumer (not just retail) demand. Having this better information enables a supplier firm to take greater advantage of flexible manufacturing facilities and better match production to demand. In this way, the returns to mutual adoption would rise as replenishment demand rose since mutual adoption would enable firms to be more effective at responding to better demand information.

\footnotetext{
${ }^{9}$ Brickley (1995) uses the fact that the firm technology adoption decisions are positively affected by certain exogenous variables to predict positive correlations between and among the endogenous choices in a cross section of firms. He finds that most pairwise correlations between franchising activities are positive and significant. He also finds that firms in non-repeat-sales industries are more likely to adopt certain clusters of practices than firms in repeat sales industries, both controlling for and not controlling for other firm characteristics. His main conclusion that complementarities exist is thus based on the finding that the correlations are positive and significant, and secondarily on the comparative statics exercises with an exogenous variable.
} 
Second, as replenishment intensity rises, the costs of excess inventories rise as well. The reason is that firms are less able to use stocks of inventory to service their customers when a larger percentage of their customers require frequent replenishment. There are increasingly deleterious managerial and production implications of holding excess inventory as a supplier in this rapid replenishment environment. Excess inventories in the form of finished or work-inprocess inventories mean higher direct costs as well as indirect costs in the forms of future markdowns of unsold goods. Thus, the returns to adoption would rise as replenishment demand rose since mutual adoption would enable firms to be more effective at providing goods more efficiently (by reducing costly excess inventories). Over time, if the strengths of complementarities rise, we should observe firms transitioning from a no innovation state to a total innovation state more often, and we should observe firms making stepwise adoptions of these technologies less often.

Unconditional correlation tests are only valid tests of complementarity to the extent that the unobserved exogenous returns that affect the individual technology choices are independent (Athey and Stern 1996). If this independence does not hold, the positive and significant correlations in Table 7 cannot be taken alone as evidence of complementarities. Arora and Gambardella (1992) point out that unconditional correlations may not be the correct test of complementarities if firm specific factors contribute to greater correlations between the choice variables. For this reason, they utilize a test of conditional correlation and find that certain strategies are correlated after controlling for firm specific traits.

In table 8, we report the correlations between the residuals from table 6 logit regressions, their significance levels, and their $95 \%$ confidence interval. All the correlation coefficients are positive but only two of the six conditional correlations are significant at the $10 \%$ level. Table 8 provides only mild evidence consistent with complementarities between the various inputs. This table indicates that more sophisticated procedures reduce the strength of the finding of static complementarities. Since gathering data about the determinants of adoption 
and including them in the analysis affects the evidence on complementarities, this illustrates that these determinants of adoption should not be neglected in studies of complementarities.

A third adoption-based test of complementarities involves estimating a reduced form model with exclusion restrictions (Athey and Stern 1996). This approach tests the null hypothesis that factors that affect the adoption decision for activities $\mathrm{j}, \mathrm{k}$, and $\mathrm{l}$ do not affect the adoption decision for activity i. We estimate an adoption model for each endogenous choice variable, controlling for factors which might affect the adoption decision of that particular innovation, as well as other exogenous parameters which should theoretically only affect the other choices. In the absence of complementarities, the coefficients on these other exogenous parameters should be zero. If complementarities exist, however, then the coefficients on these variables should be positive and jointly significant. This would demonstrate that certain factors which induce activity $\mathrm{j}$ also induce activity $\mathrm{i}$. For example, we believe that the adoption of non-proprietary barcode standards, is a unique predictor of BARCODE adoption; we do not, however, expect this instrumental variable to be related to TEAM adoption. If we find that TEAM adoption is affected by this variable, then we would have additional evidence that BARCODE and TEAM were complementary activities, since the only way TEAM would be affected by a variable like non-proprietary barcode adoption is if the returns to mutual adoption of TEAM and BARCODE rose as this exogenous factor changed.

In table 9, we test the null hypothesis that the instrumental variables (proxies for exogenous factors) are jointly significant in explaining the adoption of each individual technology. We find that instruments jointly have a significant effect only on EDI technology adoption at the $10 \%$ significance level. They do not have significant effects on the other three activities. From this reduced form exclusion restriction test, we cannot reject the null of no complementarities. This could possibly be due to the fact that the instruments themselves are not strong enough. From table 6, however, we see that the instruments are reasonably significant, except in the case of TEAM. 
A fourth possible test of complementarities involves two stage least square estimation and instrumental variables. The advantage of this approach is that we can measure the direct effect of one choice on another. The weakness of the exclusion restriction approach above is that only the net effect of an exogenous variable on the adoption choice can be measured. If we want to measure the direct effect of the choice of one technology on another, then the two stage least squares approach is more appropriate. This approach also attempts to eliminate the selection bias problem inherent in tests involving complementary inputs. A test that the coefficients on the degree of adoption, $\mathrm{y}_{\mathrm{j}}, \mathrm{y}_{\mathrm{k}}, \mathrm{y}_{\mathrm{l}}$, respectively, are different from zero in a model of the degree of adoption of technology $i, y_{i}$, would suffer from selection bias if activities are indeed complements since the error term would be correlated to the regressors. This selection bias would occur if firms that adopt a greater number of innovations do so because their expected returns to adopting are greater than firms which do not adopt several innovations at the same time. One way to avoid this selection bias problem is to test the null hypothesis that the coefficients on the predicted degree of adoption probabilities, in a linear regression of the adoption of activity $\mathrm{i}$ are individually significant via two stage least squares estimation. The issue of unobserved heterogeneity, however, cannot be eliminated, even by this approach. To believe these results, we must believe that the relevant factors of heterogeneity have been sufficiently captured by the observable variables. Table 10 does not provide strong evidence for static complementarities. Firms tend to adopt more EDI technology if they have adopted more AUTODIST technology. And firms tend to adopt more TEAM assembly methods if they have adopted more EDI. It is anomalous that the coefficients on the predicted adoption of BARCODE in the EDI, AUTODIST and TEAM equations were not significantly positive.

\section{Complementarities Among Practices: Productivity Approach}

A common method of testing for complementarities is the "productivity approach", which involves measuring the effect that practices have on firm performance and checking

10 Athey and Stern (1996) write: "Productivity analysis provides independent evidence about the benefits to adopting different practices, and the interactions between the variables." P.20. They point out that the only case 
whether interactive terms have larger effects than choice variables alone do. MacDuffie (1995) examined 62 automotive assembly plants from 1989-90 to measure the importance of complementarities. He found that combinations of employment practices rather than individual activities contribute the most to assembly plant productivity and quality when they are integrated with manufacturing changes which support a flexible production system. When each activity is included separately, the effect on productivity is approximately the same. When two or three way interactive terms are included, however, a greater part of the variance of the outcome is explained and the productivity effect increases, suggesting important interactive effects.

In another empirical study of complementarities, Brynjolffson and Hitt (1996) also find "consistent evidence of a complementarity between overall information technology (IT) spending and work systems." They find a large and significant interaction between information technology investments and adoption of "bundles" of human resource activities. The absence of similar interaction effects between IT and the other inputs (capital and labor) lead them to conclude that the IT complementarity with human resource bundles is unique. Ichniowski, Shaw, and Prennushi (1996) infer the existence of complementarities by taking a related productivity approach. They identify common clusters of practices, identifying four different employment "systems" which constitute a hierarchy from most "traditional" to most "innovative" and find that these clusters are related to productivity. They find that "clusters of complementary employment policies have large effects on productivity, while changes in individual employment practices have little or no effect on productivity."

For this study, we employ two outcome variables, operating profit margin ${ }^{11}$ and leadtime. Operating profit margin is revenue minus costs of goods sold divided by revenue and

in which productivity results are unbiased is when all unobserved heterogeneity is due to factors which affect the choices but not the outcomes.

11 Most apparel firms use relatively unsophisticated accounting methods for dealing with capital investments. Because of the phrasing of the survey question, we are unable to account explicitly for how the business unit treated capital investments. We believe, however, that this flow profitability measure is reflective of the costs of installing the new systems. 
is employed as a standard indicator of financial performance. While profit margin is a reasonable measure of the overall efficiency of the firm relative to other firms with similar cost structures it does not necessarily reflect the short run impact of certain manufacturing innovations on outcomes directly related to changing retail demand.

In order to estimate the impacts of different practices directly on replenishment-related outcomes, we use estimated supplier leadtime performance. Leadtime is calculated as the number of days that is required for an apparel manufacturer to procure, manufacture, and deliver a typical good in their product collection. The total time required in the production process includes the number of days it takes to order and receive the fabric, make the marker, cut the fabric, sew the fabric, put the product through a finishing process, ship the product to a distribution center, and then stock the product at a distribution center. The shorter the leadtime, the more quickly a firm is able to turn around a product from beginning to end. Leadtime provides a measure of the ability of a business unit to compete in a market increasingly dominated by rapid replenishment retailing principles.

Table 11a shows that firms in our sample which adopt no innovative practices earn the lowest profit margins. The relationship between the number of innovative practices adopted and performance, in terms of both profitability and leadtime, is weakly monotonic. The most innovative firms are approximately four times as profitable as the least innovative firms. Similarly, table $11 \mathrm{~b}$, suggests that the most innovative firms are able to produce and deliver their products in less than half the time of the least innovative firms. Other firm characteristics such as business unit size or product type might also be correlated with multiple innovation adoption and performance outcomes. Therefore, we would want to control for these factors before concluding that the number of innovative practices adopted has a statistically significant positive effect on profitability and leadtime.

Table 12 presents OLS estimates of the effect of innovation adoption on firm performance controlling for firm size, product type and distribution channel. We find that firms which adopt more innovations are significantly more profitable and enjoy shorter leadtimes 
than those which have adopted less. That is, firms adopting complementary inputs perform better even after controlling for important firm characteristics. This popular test for complementarities, however, suffers from potential multicollinearity and selection bias problems. If the inputs are indeed complementary, then single and interactive terms will tend to be highly correlated. Firms that adopt more "innovative" activities may do so because their expected benefits from adoption are greater or expected costs of adoption are lower than other comparable business units. If this is the case, then higher productivity effects attributed to the most "innovative" clusters may be due not to complementarities between the activities, per se, but rather to differences in underlying adoption incentives (Athey and Stern 1996).

An analysis of pairwise correlation coefficients between the various explanatory variables (available from the authors) reveal low correlations among them, which implies that results in table 12 do not suffer from multicollinearity problems. It is difficult to argue, however, that potential endogeneity biases do not exist, and therefore table 12 can be regarded as supporting evidence consistent with the hypothesis of complementarities between the various inputs, but not conclusive evidence that complementarities indeed exist.

These empirical results suggest that firms which replenish their products on a frequent basis benefit more from mutual adoption of innovative information technology, order processing, and distribution activities than do firms which do not replenish on a frequent basis. As the frequency of replenishment demand rises in the aggregate, the strength of complementarities between these practices also seems to rise. While there is some evidence that the strength of interactions grew between the two time periods among the four factors studied, these results weaken when examined with more sophisticated test of static complementarities. In particular, we find some evidence in support of static complementarities between BARCODE, EDI, and AUTODIST. We do not, however, find support for static complementarities between these three activities and TEAM. This may indicate that the observed relationships among the factors presented in earlier tables do not reflect true complementarities among the practices. Another possible reason, however, is that the timing of 
adoption varies across activities. Implicit in these tests is an assumption about the simultaneous adoption of complementary inputs. If complementary inputs are not adopted simultaneously then one may not be able to detect complementarities with cross sectional data alone. The next section further explores the sequence of adoption and its impacts on timing in examining the diffusion of modern manufacturing practices.

\section{Adoption Sequence and Tests of Complementarities}

If adoption decisions were driven solely by supply side factors (i.e. falling costs coupled with complementarities), one would expect to see differences in the adoption of modern manufacturing practices over time, but not across business units at a point in time. However, heterogeneity in adoption across business units at a point in time may emerge in the presence of complementarities if the marginal impact of those complementarities are a function of the sequence of adoption. This section examines why the sequence of adoption may matter in general to observed complementarities between practices, and in the particular case of the retail - apparel sector. It then presents evidence for these sequencing and modifies empirical tests conducted in the previous section to account for the presence of time dependent (or "dynamic") complementarities.

Hwang (1997) presents a model which integrates both supply and demand factors to explain heterogeneity in adoption timing and order of adoption across complementary inputs. The main empirical predictions of this model are that the probability of adoption rises when 1) actual demand rises, 2) input costs fall, 3) strengths of complementarities rise, or 4) adjustment costs fall. If input prices are stochastic but output prices are known, the timing of adoption may vary across firms, but the patterns of adoption will be the same across firms. If both input and output prices are stochastic and demand has an idiosyncratic component, then both the timing and sequence of adoption of inputs may vary across firms in the same industry. In this manner, the sequence of adoption is determined by how the exogenous parameters evolve over time. 
The changing organization of the retail-apparel industries suggests a particular sequence in how business units adopt the four manufacturing practices examined here. The adoption of BARCODES was a prerequisite for a system of rapid replenishment since retailers required a low cost means of collecting information at the detailed product level for their own use--an efficient method of scanning prices at the check-out register and for tracking products for internal inventory purposes. Only after a common convention on barcoding was established and in use for several years did retailers turn to systems to efficiently transmit this data to and from suppliers. ${ }^{12}$

Use of UPC barcodes followed by adoption of EDI formed the foundation for subsequent investments in practices directed towards efficient logistic management in retail distribution centers. Retailer gains from investments in advanced distribution center technologies (scanners, computer sensor controlled conveyer systems, "cross-docking" facilities that provide multiple ports for incoming and outbound trucks) were limited if they lacked a means of electronically identifying and using information concerning the contents of incoming shipments, or of connecting that information back to suppliers for purposes of invoicing. As a result, the returns to a supplier of providing customers with barcoded shipping container markers and associated practices are low absent previous investment in UPC and EDI. Making changes to the method of production to reduce manufacturing throughput times (via TEAM) also makes little sense if a business unit has not first made basic information investments necessary to carry on rapid replenishment relationships. ${ }^{13}$ Thus, from a supplier's perspective, the returns to adopting AUTODIST and TEAM are expected to be much higher

12 Case evidence from people involved in the early adoption of both UPC and EDI (members of the Food Marketing Institute, the Uniform Product Council, and individual retailers and manufacturers) indicate that the development of UPC barcodes and EDI was sequential: a system of uniform product classification was developed by a consortium of retailers and manufacturers before a similar group developed a common "platform" of electronic data interchange. However, once established the adoption of the two are reinforcing. 13 Case studies of sophisticated apparel manufacturers support this notion of sequential manufacturing investments. Levi Strauss and Haggar--two of the largest manufacturers of jeans and men's trousers--invested heavily in developing methods of uniquely identifying products and exchanging information electronically well in advance of any changes in design, cutting room, sewing, or relations with textile manufacturers (Dunlop and Weil, 1996, pp. 347-348). 
once BARCODE and EDI are already in place. Expectations of complementary interactions between these practices must therefore be overlaid by both exogenous shifts in demand (examined in Section III) and a particular sequencing story.

For an apparel business unit, there are 16 possible permutations of adoption of the four modern manufacturing practices examined in this article. These adoption permutations are denoted in Table 13 as a four digit sequence, with each adoption decision signified as either "0" for not adopted or "1" for adopted (e.g. 0000 denoting a business unit that has not adopted any of the manufacturing practices; 1100 indicating a business unit that has adopted BARCODE and EDI but not AUTODIST and TEAM; etc.). Of the 16 possible combinations, 5 conform to the expected sequence implied by the above description: BARCODE adoption as the base practice, followed only then by EDI, and then the two practices in concert with AUTODIS and / or TEAM (or $1000,1100,1110,1101$, or 1111 ). The 16 possible patterns are presented in Table 13 along with the observed 1992 frequencies of the permutations among business units in the sample. The final columns of table 13 shows that the vast majority of business units conform to just this sequencing pattern: $80 \%$ of the business units in the sample adopt the four technologies in one of the five expected sequences.

The dominant sequences in 1992 revealed in table 13 also suggest that 1992 business unit manufacturing practices should be dynamically related to 1988 business unit adoption behavior. Specifically, since we expect the marginal returns to adopting AUTODIST and TEAM to be much higher once BARCODE and EDI are in place, we hypothesize that they will be adopted sequentially after the first group of practices is put in place. The benefits of AUTODIST come from reducing the number of mistakes in reconciling shipments, the store of inventory, and the transaction costs of distribution. The benefits of TEAM come from quicker responsiveness to new demand information with reduced risk to the supplier of holding unsold finished good or work in process inventories.

Table 14 provides simple conditional probability tables to test the hypothesis that 1992 adoption of AUTODIST and TEAM is contingent on the presence of the other two 
practices in 1988. The table indicates that the probability of adopting AUTODIST and TEAM is indeed significantly higher if both BARCODE and EDI have already been adopted than if none or only one of these innovations has been adopted. The probability of adopting AUTODIST in 1992 conditional on BARCODE and EDI being adopted in 1988 is 77\% vs 47\% if BARCODE and EDI are not both present. Similarly, the probability of adopting TEAM in 1992 conditional on BARCODE and EDI being adopted in 1988 is 54\% vs 30\% if BARCODE and EDI are not both present.

Table 15 tests for dynamic complementarities (complementarities over time) in a more formal regression framework. As in previous adoption models (Table 10), we control for business unit size, product type and replenishment intensity along with practice-specific determinants. Table 15 results do not rule out other competing explanations of this lagged effect, however. For example, unobserved heterogeneity could also explain these results. It could be the case that firms which had a propensity to adopt BARCODE and EDI in 1988 also have a higher propensity to adopt AUTODIST and TEAM in 1992 simply because of some other unobserved factor, such as the presence of a more sophisticated management team. The table therefore provides consistent but not conclusive evidence for dynamic complementarities.

Table 16 uses the productivity framework for studying complementarities similar to that employed in Table 12, but explicitly testing for association between specific sequences of practices and operating profits and leadtimes. The model uses the same set of independent variables as in Table 12. However, rather than an index variable to capture the marginal impact of an additional practice (any of the four) we explicitly estimate the impact of the expected sequence of practices, beginning with BARCODE / EDI.

Several results point to the importance of sequencing in understanding diffusion of manufacturing practices. First, the presence of both BARCODE and EDI is associated with an increase in operating profits of $2.15 \%$ and reductions in leadtimes of 24 days over those firms lacking investments in either or both. These results are also more robust than those contained in Table 12. These performance results imply that other studies which have drawn on the 
productivity approach to test for complementarities without adequately modeling for particular combinations of practices (as opposed to employing a simple index of the number of practices) may not be accurately capturing the consequences of those practices. Future studies of the performance effects of complementarities must be more explicitly in their consideration of the interaction of specific practices either in relation to exogenous shifts in supply-side and/or demand-side variables.

\section{Conclusion}

Taken together, the results suggest that the diffusion of advanced manufacturing practices in the US apparel industry can be explained by the growth of rapid replenishment activity on the part of retailers coupled with dynamic complementarities between organizational design inputs. Discrete clusters of modern manufacturing practices arise cross-sectionally since firms face differing benefit and cost functions. Firms adopt innovations at different times because of differences in demand for frequent replenishment. We also find that once one complementary input is adopted, the probability of adopting the other inputs increases. Specifically, the adoption of BARCODE and EDI raised the returns to adopting AUTODIST and TEAM assembly activities. Cross-sectional heterogeneity across firms in the adoption of modern manufacturing practices is thus a natural outgrowth of the combination of complementarity dynamics and the evolution of exogenous parameters.

Empirical evidence from the US apparel industry provides three main insights to the larger study of complementarities. First, discerning the causes for observed patterns of the adoption of modern manufacturing practices (or any set of potentially complementary practices) benefits from an industry based approach that draws on detailed information on production technologies, manufacturing strategies, and product market developments. Our understanding of the role of replenishment demand and the importance of particular production sequences is an outgrowth of this industry-based empirical strategy. 
Second, this paper adds to the growing literature on the economics of modern manufacturing by providing an explanation of technology adoption based on the nature of product demand rather than input costs. Product demand is empirically found to be a key source of heterogeneity across firms. Complementarities coupled with idiosyncratic demand helps to explain why certain inputs are adopted together while other inputs are adopted in sequential order. This insight on the importance of changing product demand on manufacturing practice has wider implications. The methods of retailing described here are becoming widespread in the U.S. "Lean retailing" methods have now diffused in the retail distribution of food and groceries, consumer electronics, home building products, and most recently to the sale of automobiles.

Third, this study raises the more general question of how to test for complementarities when it takes time to adjust. We observe that firms do not necessarily adopt complementary inputs all at once but may adopt them sequentially. If choices are complements, then an increase in one choice increases the returns to the other choice. Firms which have adopted one choice in the past are more likely to adopt the others in the future. In addition to empirical implications of the need to test for complementarities in a multi-period framework, these findings have policy implications. Sequential complementarities means that firms must invest in certain subsets of practices before they can benefit from a complete system of practices. Successfully modeling which practices represent "foundations" for a new complex of organizational design features may provide the most important applied insights from the growing body of work on production complementarities. 


\section{Bibliography}

Abernathy, Fred, John Dunlop, Jan Hammond, David Weil, "The Information Integrated Channel: A Study of the US Apparel Industry in Transition," Brookings Papers on Economic Activity, 1995.

Arora, Ashish, and Alfonso Gambardella, "Complementarity and External Linkages: The Strategies of the Large Firms in Biotechnology," The Journal of Industrial Economics, Vol 38, June 1990.

Athey, Susan, and Scott Stern, "An Empirical Framework for Testing Theories About Complementarities," MIT Mimeo, May 1996.

Bagwell, Kyle, and Garey Ramey, "Coordination Economies, Advertising, and Search Behavior in Retail Markets," American Economic Review, Vol 84, 1994, p.499-517.

Brickley, James, "Incentive Conflicts and Contracting: Evidence From Franchising," Bradley Policy Research Center Working Paper 95-26, Simon School of Business, University of Rochester, Nov 1995.

Brynjolfsson, Erik, and Lorin Hitt, "Information Technology and Organizational Architecture: An Exploratory Analysis,” MIT Sloan School Mimeo, February 1996. 
Chandler, Alfred D. Jr., The Visible Hand: The Managerial Revolution in American Business, Cambridge, MA: Harvard University Press, 1977.

Dixit, Avinash, "Entry and Exit Decisions under Uncertainty," Journal of Political Economy, vol.97, no.3, 1989.

Dunlop, John T. and David Weil, "Diffusion and Performance of Modular Production in the U.S. Apparel Industry,” Industrial Relations, Vol 35, No.3, July 1996.

George, Catherine, "Work Organization and the Cost of Product Variety," Unpublished PhD Thesis, Harvard University, 1995.

Hannan, Timothy, and John M. McDowell, "The Determinants of Technology Adoption: the Case of the Banking Firm," Rand Journal of Economics, Vol 15, Autumn 1984, p.328-335.

Helper, Susan, "Supplier Relations and Adoption of New Technology: Results of Survey Research into the US Auto Industry," NBER working paper, No. 5278, Sept 1995.

Holmstrom, Bengt, and Paul Milgrom, "The Firm as an Incentive System," American Economic Review, Vol 84, Sept 1994, p.972-991.

Hwang, Margaret, "A Model of Complementarities and Investment Dynamics," Working Paper, Harvard University, February 1997.

Ichniowski, Casey, and Kathryn Shaw, and Giovanna Prennushi, "The Effects of Human Resource Management Practices on Productivity," forthcoming in American Economic Review, 1997.

Jensen, Richard, "Adoption and Diffusion of an Innovation of Uncertain Profitability," Journal of Economic Theory, Vol 27, 1982, p.182-193.

Little, Roderick and Donald Rubin, Statistical Analysis with Missing Data, New York, John Wiley and Sons, 1987.

Little, Roderick, Donald Rubin, Nathaniel Schenker, “An Overview of Methods for Dealing with Missing Data,” Harvard Statistics Department Mimeo, Sept 1995.

Liu, Chuan Hai, "Bartletts Decomposition of the Posterior Distribution" The Journal of Multivariate Analysis, 1994.

Liu, Chuan Hai, "Missing Data Imputation Using the Multivariate T-Distribution" The Journal of Multivariate Analysis, 1995. 
MacDuffie, John Paul, "Human Resource Bundles and Manufacturing Performance: Organizational Logic and Flexible Production Systems in the World Auto Industry," Industrial and Labor Relations Review, Vol 48, No.2, January 1995.

Milgrom, Paul and John Roberts, "The Economics of Modern Manufacturing," American Economic Review, Vol 80, June 1990, p.511-528.

Milgrom, Paul, Yingyi Qian, and John Roberts, "Complementarities, Momentum, and the Evolution of Modern Manufacturing," American Economic Review, Vol 81, May 1991, p.84-88.

Milgrom, Paul, and John Roberts, "Complementarities and Fit: Strategy, Structure, and Organizational Change in Manufacturing," Journal of Accounting and Economics, Vol 19, 1995, p.179-208.

Pashigian, Peter B., "Demand Uncertainty and Sales: A Study of Fashion and Markdown Pricing." American Economic Review, Vol 78, Dec 1988, pp. 936-953.

Pindyck, Robert S., "Irreversible Investment, Capacity Choice, and the Value of the Firm," American Economic Review, Vol 78, Dec 1988, p.969-985.

Rubin, Donald, Multiple Imputation for Nonresponse in Surveys, New York, John Wiley and Sons, 1987. 
Table 1: Replenishment Rates by Retail Channels, 1988 and 1992

\begin{tabular}{|c|c|c|c|c|}
\hline TABLE 1a & \multicolumn{4}{|c|}{ MASS MERCHANTS } \\
\hline $\begin{array}{l}\text { avg \% sales replenished } \\
\text { at different frequencies }\end{array}$ & 1988 & 1992 & diff & p-value \\
\hline Daily & 1.49 & 8.38 & 6.89 & 0.0070 \\
\hline Weekly & 5.40 & 34.06 & 28.65 & 0.0000 \\
\hline BiWeekly & 3.56 & 11.07 & 7.52 & 0.0002 \\
\hline Monthly & 17.31 & 23.82 & 6.51 & 0.1585 \\
\hline Never & 68.96 & 22.90 & -46.06 & 0.0000 \\
\hline Total & $100 \%$ & $100 \%$ & & \\
\hline$\%$ of all sales & $26 \%$ & $27 \%$ & & \\
\hline TABLE $1 \mathrm{~b}$ & \multicolumn{4}{|c|}{ NATIONAL CHAINS } \\
\hline $\begin{array}{l}\text { avg \% sales replenished } \\
\text { at different frequencies }\end{array}$ & 1988 & 1992 & diff & p-value \\
\hline Daily & 0.72 & 8.90 & 8.17 & 0.0010 \\
\hline Weekly & 7.46 & 33.61 & 26.15 & 0.0000 \\
\hline BiWeekly & 5.70 & 8.81 & 3.11 & 0.2085 \\
\hline Monthly & 26.19 & 23.59 & -2.60 & 0.5959 \\
\hline Never & 56.04 & 25.10 & -30.94 & 0.0000 \\
\hline Total & $100 \%$ & $100 \%$ & & \\
\hline$\%$ of all sales & $18 \%$ & $14 \%$ & & \\
\hline TABLE 1c & \multicolumn{4}{|c|}{ DEPARTMENT STORES } \\
\hline $\begin{array}{l}\text { avg \% sales replenished } \\
\text { at different frequencies }\end{array}$ & 1988 & 1992 & diff & p-value \\
\hline Daily & 0.00 & 0.05 & 0.05 & 0.290 \\
\hline Weekly & 1.92 & 26.70 & 24.78 & 0.0000 \\
\hline BiWeekly & 3.41 & 11.95 & 8.54 & 0.001 \\
\hline Monthly & 31.74 & 38.83 & 7.10 & 0.187 \\
\hline Never & 60.51 & 22.22 & -38.29 & 0.0000 \\
\hline Total & $100 \%$ & $100 \%$ & & \\
\hline$\%$ of all sales & $28 \%$ & $32 \%$ & & \\
\hline
\end{tabular}

\begin{tabular}{|l|c|c|c|c|}
\hline TABLE 1d & \multicolumn{4}{|c|}{ ALL CHANNELS } \\
\hline $\begin{array}{l}\text { avg \% sales replenished } \\
\text { at different frequencies }\end{array}$ & 1988 & 1992 & diff & p-value \\
\hline Daily & 1.56 & 3.74 & 2.18 & 0.1384 \\
\hline Weekly & 7.17 & 30.14 & 22.98 & 0.0000 \\
\hline BiWeekly & 3.56 & 11.07 & 7.52 & 0.0002 \\
\hline Monthly & 26.03 & 30.71 & 4.67 & 0.2532 \\
\hline Never & 61.69 & 22.52 & -39.17 & 0.0000 \\
\hline Total & $100 \%$ & $100 \%$ & & \\
\hline
\end{tabular}




\section{Table 2a:Technology Adoption Over Time}

\section{Percent of Firms Using Each Technology}

\begin{tabular}{cccccc} 
Technology & 1988 & 1992 & Diff & t stat & Pvalue \\
\hline BARCODE & $53.9 \%$ & $74.5 \%$ & $38.1 \%$ & 7.34 & 0.00 \\
EDI & $33.2 \%$ & $83.3 \%$ & $50.0 \%$ & 9.02 & 0.00 \\
AUTODIST & $26.9 \%$ & $46.6 \%$ & $36.1 \%$ & 6.62 & 0.00 \\
TEAM & $14.6 \%$ & $29.6 \%$ & $28.6 \%$ & 5.44 & 0.00
\end{tabular}

Table 2b: Technology Adoption Over Time

Percent of Sales Involving Each Technology

\begin{tabular}{cccccc} 
Technology & 1988 & 1992 & Diff & t stat & Pvalue \\
\hline BARCODE & $24.7 \%$ & $59.5 \%$ & $34.8 \%$ & 7.99 & 0.00 \\
EDI & $5.1 \%$ & $33.6 \%$ & $28.5 \%$ & 9.89 & 0.00 \\
AUTODIST & $8.2 \%$ & $33.2 \%$ & $25.0 \%$ & 6.02 & 0.00
\end{tabular}

Table 2c: Technology Adoption Over Time

Percent of Sales Involving Each Technology Among Firms Using the Technology

\begin{tabular}{ccc} 
Technology & 1988 & 1992 \\
\hline BARCODE & $54.7 \%$ & $71.5 \%$ \\
& $(39.27)$ & $(36.11)$ \\
EDI & $15.4 \%$ & $40.4 \%$ \\
& $(20.36)$ & $(29.39)$ \\
AUTODIST & $44.3 \%$ & $60.1 \%$ \\
& $(42.45)$ & $(39.40)$ \\
TEAM & -- & $29.6 \%$ \\
& & $(36.86)$
\end{tabular}

standard deviation in parentheses

BARCODE = products are marked with UPC barcodes at the SKU level.

EDI $\quad=$ purchase orders received via electronic data interchange.

AUTODIST = shipments use containers marked with a barcoded marker.

TEAM = domestic sewing output produced using modular or team assembly systems. 


\section{Table 3: Frequency of Adopting Technology Pairs}

BARCODE and EDI

\begin{tabular}{|c|c|c|}
\hline 1988 & \multicolumn{2}{|c|}{ EDI } \\
\hline BARCODE & no & yes \\
\hline no & $\mathbf{4 6 . 8 \%}$ & $8.0 \%$ \\
\hline yes & $19.9 \%$ & $\mathbf{2 5 . 2 \%}$ \\
\hline
\end{tabular}

\begin{tabular}{|c|c|c|}
\hline 1992 & \multicolumn{2}{|c|}{ EDI } \\
\hline BARCODE & no & yes \\
\hline no & $\mathbf{8 . 0 \%}$ & $8.7 \%$ \\
\hline yes & $8.7 \%$ & $\mathbf{7 4 . 5 \%}$ \\
\hline
\end{tabular}

BARCODE and AUTODIST

\begin{tabular}{|c|c|c|}
\hline 1988 & \multicolumn{2}{|c|}{ AUTODIST } \\
\hline BARCODE & no & yes \\
\hline no & $\mathbf{5 0 . 5 \%}$ & $4.4 \%$ \\
\hline yes & $30.8 \%$ & $\mathbf{1 4 . 3 \%}$ \\
\hline
\end{tabular}

\begin{tabular}{|c|c|c|}
\hline 1992 & \multicolumn{2}{|c|}{ AUTODIST } \\
\hline BARCODE & no & yes \\
\hline no & $\mathbf{1 1 . 4 \%}$ & $5.3 \%$ \\
\hline yes & $33.7 \%$ & $\mathbf{4 9 . 5 \%}$ \\
\hline
\end{tabular}

\section{EDI and AUTODIST}

\begin{tabular}{|c|c|c|}
\hline 1988 & \multicolumn{2}{|c|}{ AUTODIST } \\
\hline EDI & no & yes \\
\hline no & $\mathbf{6 0 . 9 \%}$ & $5.8 \%$ \\
\hline yes & $20.4 \%$ & $\mathbf{1 2 . 9 \%}$ \\
\hline
\end{tabular}

\begin{tabular}{|c|c|c|}
\hline 1992 & \multicolumn{2}{|c|}{ AUTODIST } \\
\hline EDI & no & yes \\
\hline no & $\mathbf{1 3 . 6 \%}$ & $3.1 \%$ \\
\hline yes & $31.6 \%$ & $\mathbf{5 1 . 7 \%}$ \\
\hline
\end{tabular}

BARCODE = products marked with UPC barcodes at the SKU level.

EDI $=$ purchase orders received via electronic data interchange.

AUTODIST = shipments using containers marked with a barcoded marker.

TEAM = domestic sewing output produced using modular or team assembly systems. 


\section{Table 4: Conditional Probability of Technology Adoption}

A. Probability of Adopting EDI conditional on BARCODE

1988

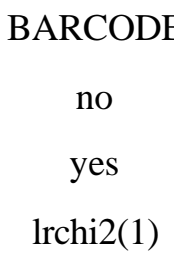

EDI

\begin{tabular}{|cc|}
\multicolumn{1}{c}{ no } & yes \\
\hline 85.44 & 14.56 \\
44.06 & 55.94 \\
\hline 17.84 & $(0.0038)$ \\
\hline
\end{tabular}

1992

BARCODE
no
yes
$\operatorname{lrchi} 2(1)$

EDI

\begin{tabular}{|cc|}
\multicolumn{1}{c}{ no } & yes \\
\hline 38.89 & 61.11 \\
10.59 & 89.41 \\
\hline 9.31 & $(0.0514)$ \\
\hline
\end{tabular}

B. Probability of Adopting AUTODIST conditional on BARCODE

$$
1988
$$

\section{BARCODE}

no

yes

$\operatorname{lrchi} 2(1)$
AUTODIST

no

\begin{tabular}{|cc|}
\hline 96.43 & 3.57 \\
70.21 & 29.79 \\
\hline 10.13 & $(0.0222)$ \\
\hline
\end{tabular}

1992

BARCODE

no

yes

$\operatorname{lrchi} 2(1)$

\begin{tabular}{|cc|}
\multicolumn{2}{|c}{ AUTODIST } \\
no & yes \\
\hline 61.11 & 38.89 \\
37.65 & 62.35 \\
\hline 4.81 & $(0.0710)$ \\
\hline
\end{tabular}

C. Probability of Adopting TEAM conditional on BARCODE

1988

\section{BARCODE}

no
yes
$\operatorname{lrchi} 2(1)$

TEAM

\begin{tabular}{|cc|}
\multicolumn{1}{c}{ no } & yes \\
\hline 92.86 & 7.14 \\
91.49 & 8.51 \\
\hline 0.09 & $(0.7759)$ \\
\hline
\end{tabular}

1992

BARCODE

no
yes
$\operatorname{lrchi} 2(1)$

TEAM

\begin{tabular}{|cc|}
\multicolumn{1}{c}{ no } & yes \\
\hline 61.11 & 38.89 \\
63.53 & 36.47 \\
\hline 1.20 & $(0.3818)$ \\
\hline
\end{tabular}

Note: $\operatorname{lrchi}(1)=$ chi-squared likelihood ratio test with one degree of freedom which tests Null hypothesis that conditional probabilities are the same betwen the upper and lower rows. P-values are in parentheses.

BARCODE = products marked with UPC barcodes at the SKU level.

EDI $\quad=$ purchase orders received via electronic data interchange.

AUTODIST = shipments using containers marked with a barcoded marker.

TEAM = domestic sewing output produced using modular or team assembly systems.

Table 4: Conditional Probability of Technology Adoption (continued) 
D. Probability of Adopting AUTODIST conditional on EDI

\begin{tabular}{cccccc}
1988 & \multicolumn{2}{c}{ AUTODIST } & \multicolumn{2}{c}{1992} & \multicolumn{2}{c}{ AUTODIST } \\
EDI & no & yes & EDI & no & yes \\
no & 91.29 & 8.72 & no & 81.25 & 18.75 \\
yes & 61.32 & 38.68 & yes & 34.48 & 65.52 \\
\cline { 2 - 3 } lrchi(1) & 13.22 & $(0.0015)$ & lrchi2(1) & 9.11 & $(0.0240)$
\end{tabular}

E. Probability of Adopting TEAM conditional on EDI

\begin{tabular}{|c|c|c|c|c|c|}
\hline 1988 & \multicolumn{2}{|c|}{ TEAM } & 1992 & \multicolumn{2}{|c|}{ TEAM } \\
\hline EDI & no & yes & EDI & no & yes \\
\hline no & 92.00 & 8.00 & no & 75.00 & 25.00 \\
\hline yes & 92.70 & 7.30 & yes & 60.92 & 39.08 \\
\hline $\operatorname{lrchi}(1)$ & 0.17 & $(0.7051)$ & $\operatorname{lrchi} 2(1)$ & 0.92 & $(0.4717)$ \\
\hline
\end{tabular}

F. Probability of Adopting TEAM conditional on AUTODIST

1988

AUTODIST

no
yes
$\operatorname{lrchi}(1)$

TEAM

\begin{tabular}{|cc|}
\multicolumn{1}{c}{ no } & yes \\
\hline 92.82 & 7.18 \\
89.29 & 10.71 \\
\hline 0.29 & $(0.6394)$ \\
\hline
\end{tabular}

1992 AUTODIST

no
yes
lrchi2(1)

TEAM

\begin{tabular}{|cc|}
\multicolumn{1}{c}{ no } & yes \\
\hline 69.77 & 30.23 \\
58.33 & 41.67 \\
\hline 1.55 & $(0.3046)$ \\
\hline
\end{tabular}

Note: $\operatorname{lrchi}(1)=$ chi-squared likelihood ratio test with one degree of freedom which tests Null hypothesis that conditional probabilities are the same betwen the upper and lower rows. P-values are in parentheses.

BARCODE = products marked with UPC barcodes at the SKU level.

EDI $=$ purchase orders received via electronic data interchange.

AUTODIST = shipments using containers marked with a barcoded marker.

TEAM = domestic sewing output produced using modular or team assembly systems. 


\section{Table 5: The Impact of Replenishment Pressure on Technology Adoption}

\begin{tabular}{ccccccc}
\multicolumn{6}{c}{ Percent of Firms Adopting a Technology under Different Replenishment ${ }^{* *}$ Frequencies } \\
1988 & Low Replenishment & High Replenishment & diff & t-stat & df & pvalue \\
\hline BARCODE & 0.3829 & 0.6963 & 0.3134 & 2.80 & 36 & 0.0041 \\
& $(0.4888)$ & $(0.4658)$ & & & & \\
EDI & 0.2931 & 0.4742 & 0.1811 & 1.53 & 32 & 0.0679 \\
& $(0.4574)$ & $(0.5094)$ & & & & \\
AUTODIST & 0.1797 & 0.2087 & 0.0290 & 0.30 & 33 & 0.3832 \\
& $(0.3832)$ & $(0.4138)$ & & & & \\
TEAM & 0.0622 & 0.1326 & 0.0704 & 0.91 & 28 & 0.1860 \\
& $(0.2434)$ & $(0.3466)$ & & & & \\
& & & & & & \\
1992 & Low Replenishment & High Replenishment & diff & t-stat & df & pvalue \\
\hline BARCODE & 0.7843 & 0.8797 & 0.0954 & 1.29 & 95 & 0.0996 \\
& $(0.4147)$ & $(0.3282)$ & & & & \\
EDI & 0.7646 & 0.8990 & 0.1344 & 1.85 & 90 & 0.0336 \\
AUTODIST & $(0.4244)$ & $(0.3000)$ & & & & \\
& 0.4216 & 0.6730 & 0.2514 & 2.63 & 100 & 0.0050 \\
TEAM & $(0.4976)$ & $(0.4721)$ & & & & \\
& 0.2942 & 0.4328 & 0.1385 & 1.47 & 101 & 0.0722 \\
\hline
\end{tabular}

** Firms face "high replenishment" demand if the percent of their sales to mass merchants and national chains replenished on a daily or weekly basis is higher than the industry median. Otherwise, they face "low replenishment"demand. 


\section{Table 6a: Determinants of Technology Adoption (MLE Logit Models)}

\begin{tabular}{|c|c|c|c|c|}
\hline $\begin{array}{l}\text { Independent Variables } \\
\text { (Variable mean in parenthesis below) }\end{array}$ & BARCODE $^{\ominus}$ & $\mathrm{EDI}^{\ominus}$ & AUTODIST $^{\circ}$ & TEAM $^{\diamond}$ \\
\hline Constant & $\begin{array}{l}-1.0563 \\
(1.1758) \\
{[0.1877]}\end{array}$ & $\begin{array}{c}-2.7558 * * \\
(1.5776) \\
{[0.0489]}\end{array}$ & $\begin{array}{l}-2.0071 \\
(1.6386) \\
{[0.1376]}\end{array}$ & $\begin{array}{l}-1.1281 \\
(1.3859) \\
{[0.2173]}\end{array}$ \\
\hline $\begin{array}{c}\text { replenishment Intensity } \\
(29 \%)\end{array}$ & $\begin{array}{l}0.0169^{*} \\
(0.0125) \\
{[0.0886]}\end{array}$ & $\begin{array}{c}0.0176 \\
(0.0182) \\
{[0.1747]}\end{array}$ & $\begin{array}{l}0.0139 * * \\
(0.0082) \\
{[0.0454]}\end{array}$ & $\begin{array}{c}0.0068 \\
(0.0093) \\
{[0.2369]}\end{array}$ \\
\hline $\begin{array}{c}\log \text { Sales } 1992 \\
(4.09)\end{array}$ & $\begin{array}{c}0.2164 \\
(0.2451) \\
{[0.1902]}\end{array}$ & $\begin{array}{l}0.6188^{*} \\
(0.3706) \\
{[0.0566]}\end{array}$ & $\begin{array}{c}0.2353 \\
(0.2959) \\
{[0.2263]}\end{array}$ & $\begin{array}{c}0.2874 \\
(0.2945) \\
{[0.1834]}\end{array}$ \\
\hline $\begin{array}{c}\text { \% "Basic" Products } \\
(38 \%)\end{array}$ & $\begin{array}{l}0.0191^{*} \\
(0.0127) \\
{[0.0691]}\end{array}$ & $\begin{array}{l}0.0219^{*} \\
(0.0160) \\
{[0.0910]}\end{array}$ & $\begin{array}{c}0.0014 \\
(0.0089) \\
{[0.4371]}\end{array}$ & $\begin{array}{l}-0.0038 \\
(0.0088) \\
{[0.3323]}\end{array}$ \\
\hline $\begin{array}{c}\text { non-Proprietary Barcodes } \\
(82 \%)\end{array}$ & $\begin{array}{l}1.2004 * \\
(0.7980) \\
{[0.0725]} \\
\end{array}$ & & & \\
\hline $\begin{array}{c}\text { POS Data Received } \\
(70 \%)\end{array}$ & & $\begin{array}{c}2.1567 * * \\
(0.7038) \\
{[0.0011]} \\
\end{array}$ & & \\
\hline $\begin{array}{l}\text { ASN Received } \\
(53 \%)\end{array}$ & & & $\begin{array}{l}1.5970 * * \\
(0.5627) \\
{[0.0036]}\end{array}$ & \\
\hline $\begin{array}{l}\text { participation } \\
\quad(-2.3)\end{array}$ & & & & $\begin{array}{c}0.2909 \\
(0.3146) \\
{[0.1791]}\end{array}$ \\
\hline $\begin{array}{c}\text { direct labor costs } \\
(9.7)\end{array}$ & & & & $\begin{array}{l}-0.0026 \\
(0.0203) \\
{[0.4504]}\end{array}$ \\
\hline F-statistic & 4.85 & 3.37 & 2.20 & 1.16 \\
\hline number of observations & 103 & 103 & 103 & 103 \\
\hline
\end{tabular}

$\checkmark$ Dependent variables equal 1 if the technology is adopted, 0 otherwise.

* indicates significance at $10 \%$ level

** indicates significance at $5 \%$ level

( ) Standard errors appear in parentheses

[ ] p-values appear in brackets

Independent variables are defined as follows:

- replenishment intensity is the percent of sales to mass merchants and national chains replenished on a daily/weekly basis.

- $\quad$ log sales 1992 is the natural logarithm of net sales in 1992. Sales are in millions of dollars.

- \% "basic" products is the percent sales of a basic (vs fashion) type.

- non-proprietory barcodes indicates use of a non-proprietary bar code standard.

- POS data received indicates that the firm receives point of sale information.

- ASN provided indicates that advanced shipping notice is used.

- direct labor costs are measured in dollars per unit.

- participation is a categorical variable for participation in Quick Response programs by manufacturing personnel. The higher the variable, the more involved were the personnel. 
Table 6b: Impact of Explanatory Variables on the Probability of Adoption

Change in the probability of adoption resulting from a one standard deviation change in the $\mathrm{X}$ variable

\begin{tabular}{|c|c|c|c|c|c|}
\hline variable: & one std dev & BARCODE & EDI & AUTODIST & TEAM \\
\hline $\begin{array}{l}\text { replenishment } \\
\text { intensity }\end{array}$ & $33 \%$ & $5.68 \%$ & $3.63 \%$ & $11.29 \%$ & $5.15 \%$ \\
\hline log sales 1992 & 1.45 & $3.19 \%$ & $5.60 \%$ & $8.38 \%$ & $9.53 \%$ \\
\hline $\begin{array}{l}\% \text { "basic" } \\
\text { products }\end{array}$ & $32 \%$ & $6.29 \%$ & $4.43 \%$ & $1.12 \%$ & $-2.82 \%$ \\
\hline $\begin{array}{c}\text { Non-Proprietary } \\
\text { barcodes }\end{array}$ & 1 & $12.19 \%$ & & & \\
\hline $\begin{array}{l}\text { POS data } \\
\text { received }\end{array}$ & 1 & & $13.44 \%$ & & \\
\hline ASN provided & 1 & & & $39.25 \%$ & \\
\hline participation & 1 & & & & $6.65 \%$ \\
\hline direct labor costs & 15 & & & & $-0.91 \%$ \\
\hline $\begin{array}{c}\text { Average Adoption } \\
\text { Probability* }\end{array}$ & & $88 \%$ & $93 \%$ & $56 \%$ & $35 \%$ \\
\hline
\end{tabular}

- Probabilities are evaluated at the average values of the explanatory variables.

- This table is derived from Table 5a. 


\section{Table 7: Correlation between Exogenous Parameter \& Endogenous Choices}

$\begin{array}{ccccc}1988 & \begin{array}{c}\text { Replenishment } \\ \text { Intensity } \\ 1.00\end{array} & \text { BARCODE } & \text { EDI } & \text { AUTODIST } \\ \begin{array}{c}\text { Replenishment } \\ \text { Intensity }\end{array} & & & & \\ \text { BARCODE } & 0.186^{*} & 1.00 & & \\ & (2.823) & & & \\ \text { EDI } & {[0.096]} & & & \\ & 0.142 & 0.256^{*} & 1.00 & \\ \text { AUTODIST } & (1.922) & (3.805) & & 1.00 \\ & {[0.166]} & {[0.068]} & & \\ & -0.021 & 0.449^{*} & 0.270^{*} & \\ \text { TEAM } & (0.042) & (13.486) & (5.509) & \text { na }\end{array}$

$\begin{array}{ccccc}1992 & \begin{array}{c}\text { Replenishment } \\ \text { Intensity } \\ 1.00\end{array} & \text { BARCODE } & \text { EDI } & \text { AUTODIST } \\ \begin{array}{c}\text { Replenishment } \\ \text { Intensity }\end{array} & & & & \\ \text { BARCODE } & 0.425^{*} & 1.00 & & \\ & (15.122) & & & \\ \text { EDI } & {[0.000]} & & 1.00 & \\ & 0.524^{*} & 0.375^{*} & & \\ \text { AUTODIST } & (18.448) & (6.737) & & \\ & {[0.000]} & {[0.025]} & & \\ & 0.227^{*} & 0.229^{*} & 0.359^{*} & \\ \text { TEAM } & (2.811) & (4.832) & (10.023) & \\ & {[0.116]} & {[0.028]} & {[0.002]} & 0.164 \\ & 0.087 & -0.008 & 0.106 & (2.153) \\ & (0.292) & (0.002) & (0.243) & {[0.146]}\end{array}$

( ) t-statistics are in parentheses

[] p-values are in brackets 
Table 8: Conditional Correlations

Correlation Coefficients of the Residuals from Logit Regressions in table 6

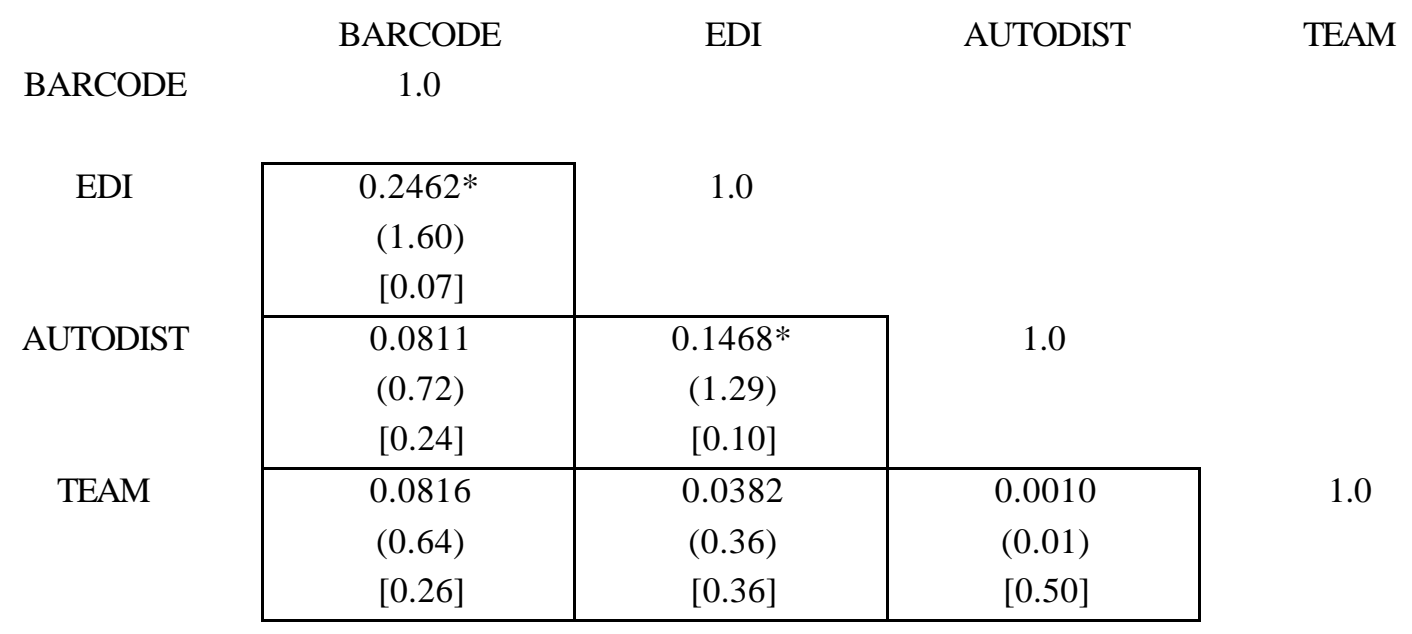

* indicates significance at $10 \%$ level for one-tailed t-test

( ) t-statistics are in parentheses

[ ] p-values are in brackets 
Table 9: Reduced Form Regressions with Exclusion Restrictions

\begin{tabular}{|c|c|c|c|c|}
\hline & $\operatorname{logit}(\mathrm{BARCODE})$ & $\operatorname{logit}(\mathrm{EDI})$ & logit(AUTODIST) & $\operatorname{logit}(\mathrm{TEAM})$ \\
\hline Constant & $\begin{array}{c}-7.5497 * * \\
(3.9686) \\
{[0.0297]} \\
\end{array}$ & $\begin{array}{c}-8.3596 * * \\
(3.2637) \\
{[0.0168]} \\
\end{array}$ & $\begin{array}{c}-7.7468 * \\
(5.8711) \\
{[0.1082]} \\
\end{array}$ & $\begin{array}{c}-8.7247 * * \\
(2.9446) \\
{[0.0026]} \\
\end{array}$ \\
\hline $\begin{array}{l}\text { replenishment } \\
\text { intensity }\end{array}$ & $\begin{array}{c}0.0549 * * \\
(0.0266) \\
{[0.02]} \\
\end{array}$ & $\begin{array}{c}0.0209 \\
(0.017) \\
{[0.1152]}\end{array}$ & $\begin{array}{c}0.0335 \\
(0.0343) \\
{[0.1706]} \\
\end{array}$ & $\begin{array}{c}0.0168 \\
(0.028) \\
{[0.2821]} \\
\end{array}$ \\
\hline log sales 1992 & $\begin{array}{c}0.6521 \\
(0.6159) \\
{[0.1452]} \\
\end{array}$ & $\begin{array}{c}0.1094 \\
(0.5387) \\
{[0.4224]}\end{array}$ & $\begin{array}{c}1.1045 \\
(0.9118) \\
{[0.1245]} \\
\end{array}$ & $\begin{array}{c}0.3653 \\
(0.7633) \\
{[0.3246]} \\
\end{array}$ \\
\hline \% "basic" products & $\begin{array}{c}0.0269 \\
(0.0307) \\
{[0.1933]}\end{array}$ & $\begin{array}{c}0.0328 * * \\
(0.016) \\
{[0.0221]}\end{array}$ & $\begin{array}{c}0.0112 \\
(0.0324) \\
{[0.3655]}\end{array}$ & $\begin{array}{l}-0.014 \\
(0.0221) \\
{[0.2658]}\end{array}$ \\
\hline $\begin{array}{l}\text { non-proprietary } \\
\text { barcodes }\end{array}$ & $\begin{array}{c}4.1028 * * \\
(2.3248) \\
{[0.0412]} \\
\end{array}$ & $\begin{array}{c}0.6366 \\
(1.9798) \\
{[0.3786]} \\
\end{array}$ & $\begin{array}{l}-0.3249 \\
(2.7624) \\
{[0.4537]} \\
\end{array}$ & $\begin{array}{l}-2.6781 * \\
(2.0298) \\
{[0.1069]} \\
\end{array}$ \\
\hline POS data received & $\begin{array}{c}0.6699 \\
(1.9448) \\
{[0.3657]} \\
\end{array}$ & $\begin{array}{c}3.0716 * * \\
(1.2033) \\
{[0.0091]} \\
\end{array}$ & $\begin{array}{l}-0.2353 \\
(2.2239) \\
{[0.4582]}\end{array}$ & $\begin{array}{l}2.0388 * \\
(1.4584) \\
{[0.0866]} \\
\end{array}$ \\
\hline ASN provided & $\begin{array}{c}0.1186 \\
(1.809) \\
{[0.4739]}\end{array}$ & $\begin{array}{c}2.8592 * * \\
(1.201) \\
{[0.0143]}\end{array}$ & $\begin{array}{c}6.0489 * * \\
(2.1647) \\
{[0.0041]} \\
\end{array}$ & $\begin{array}{c}1.3611 \\
(1.3929) \\
{[0.168]}\end{array}$ \\
\hline $\begin{array}{c}\text { participation of mfg } \\
\text { personnel }\end{array}$ & $\begin{array}{l}-0.7261 \\
(1.1206) \\
{[0.2595]} \\
\end{array}$ & $\begin{array}{c}0.1474 \\
(0.7862) \\
{[0.4273]} \\
\end{array}$ & $\begin{array}{c}1.6903 * \\
(1.2592) \\
{[0.0933]} \\
\end{array}$ & $\begin{array}{c}0.3761 \\
(0.9566) \\
{[0.3503]} \\
\end{array}$ \\
\hline direct labor costs & $\begin{array}{c}-0.1223 * \\
(0.0802) \\
{[0.0766]}\end{array}$ & $\begin{array}{c}0.0094 \\
(0.0489) \\
{[0.4256]} \\
\end{array}$ & $\begin{array}{c}0.0058 \\
(0.0928) \\
{[0.4758]} \\
\end{array}$ & $\begin{array}{c}0.0067 \\
(0.0541) \\
{[0.4514]} \\
\end{array}$ \\
\hline F-statistic & 2.83 & 4.36 & 2.90 & 13.70 \\
\hline nobs & 103 & 103 & 103 & 103 \\
\hline $\begin{array}{c}\mathrm{H}_{0}: \mathrm{IV}_{\mathrm{i}}=0 \forall_{\mathrm{i}} \\
\text { F-test } \\
\text { p-value }\end{array}$ & $\begin{array}{c}1.276 \\
0.2794\end{array}$ & $\begin{array}{c}2.136 \\
0.0893\end{array}$ & $\begin{array}{l}1.7660 \\
0.1298\end{array}$ & $\begin{array}{c}.8000 \\
0.5560\end{array}$ \\
\hline
\end{tabular}

* indicates significance at $10 \%$ level

** indicates significance at $5 \%$ level

( ) Standard errors appear in parentheses

[ ] p-values appear in brackets 
Table 10: 2SLS Regressions of Technology Adoption

\begin{tabular}{|c|c|c|c|c|}
\hline & $\operatorname{logit}(\mathrm{BARCODE})$ & $\operatorname{logit}(E D I)$ & $\operatorname{logit}($ AUTODIST) & $\operatorname{logit}($ TEAM) \\
\hline Constant & $\begin{array}{c}-37.6210 \\
(45.2273) \\
{[0.2148]}\end{array}$ & $\begin{array}{c}-0.9845 \\
(15.4882) \\
{[0.4747]}\end{array}$ & $\begin{array}{c}-5.5994 \\
(49.9820) \\
{[0.4570]}\end{array}$ & $\begin{array}{c}-5.9112 \\
(7.3812) \\
{[0.2248]}\end{array}$ \\
\hline $\begin{array}{c}\text { predicted } \\
\text { BARCODE }^{\circ}\end{array}$ & & $\begin{array}{c}0.1294 \\
(0.5403) \\
{[0.4093]}\end{array}$ & $\begin{array}{l}-0.0654 \\
(0.7313) \\
{[0.4647]}\end{array}$ & $\begin{array}{l}-0.7235 \\
(0.6621) \\
{[0.1582]}\end{array}$ \\
\hline $\begin{array}{l}\text { predicted } \\
\mathrm{EDI}^{\circ}\end{array}$ & $\begin{array}{c}0.1573 \\
(0.6735) \\
{[0.4085]}\end{array}$ & & $\begin{array}{l}-0.1046 \\
(0.7049) \\
{[0.4414]}\end{array}$ & $\begin{array}{l}0.5925^{*} \\
(0.3798) \\
{[0.0596]}\end{array}$ \\
\hline $\begin{array}{c}\text { predicted } \\
\text { AUTODIST }^{\circ}\end{array}$ & $\begin{array}{c}0.1021 \\
(0.3335) \\
{[0.3803]}\end{array}$ & $\begin{array}{c}0.4947 * \\
(0.2710) \\
{[0.0553]}\end{array}$ & & $\begin{array}{c}0.2220 \\
(0.2251) \\
{[0.1640]}\end{array}$ \\
\hline $\begin{array}{c}\text { predicted } \\
\text { TEAM }^{\circ}\end{array}$ & $\begin{array}{l}-3.2105 \\
(4.3076) \\
{[0.2366]}\end{array}$ & $\begin{array}{c}0.0107 \\
(1.7057) \\
{[0.4975]}\end{array}$ & $\begin{array}{c}-0.1023 \\
(5.9057) \\
{[0.4934]}\end{array}$ & \\
\hline $\begin{array}{l}\text { replenishment } \\
\text { intensity }\end{array}$ & $\begin{array}{c}0.1359 \\
(0.1363) \\
{[0.1761]}\end{array}$ & $\begin{array}{l}-0.0137 \\
(0.0505) \\
{[0.3936]}\end{array}$ & $\begin{array}{c}0.0210 \\
(0.1250) \\
{[0.4346]}\end{array}$ & $\begin{array}{c}0.0361 \\
(0.0589) \\
{[0.2812]}\end{array}$ \\
\hline log sales 1992 & $\begin{array}{c}2.0342 \\
(4.1872) \\
{[0.3238]}\end{array}$ & $\begin{array}{l}-0.6231 \\
(1.1683) \\
{[0.2975]}\end{array}$ & $\begin{array}{l}-0.5582 \\
(2.3920) \\
{[0.4080]}\end{array}$ & $\begin{array}{c}0.3425 \\
(1.1677) \\
{[0.3896]}\end{array}$ \\
\hline \% "basic" products & $\begin{array}{l}-0.0451 \\
(0.1458) \\
{[0.3837]}\end{array}$ & $\begin{array}{c}0.0263 \\
(0.0508) \\
{[0.3035]}\end{array}$ & $\begin{array}{c}0.0053 \\
(0.1594) \\
{[0.4872]}\end{array}$ & $\begin{array}{l}-0.0091 \\
(0.0354) \\
{[0.3997]}\end{array}$ \\
\hline $\begin{array}{l}\text { non-proprietary } \\
\text { barcodes }\end{array}$ & $\begin{array}{c}4.0294 * * \\
(2.3621) \\
{[0.0465]}\end{array}$ & & & \\
\hline POS data received & & $\begin{array}{c}3.0405 * * \\
(1.1329) \\
{[0.0056]}\end{array}$ & & \\
\hline ASN provided & & & $\begin{array}{c}5.9081 * * \\
(2.1639) \\
{[0.0050]}\end{array}$ & \\
\hline $\begin{array}{l}\text { participation of mfg } \\
\text { personnel }\end{array}$ & & & & $\begin{array}{c}0.3761 \\
(0.9566) \\
{[0.3503]}\end{array}$ \\
\hline direct labor costs & & & & $\begin{array}{c}0.0067 \\
(0.0541) \\
{[0.4514]}\end{array}$ \\
\hline F-statistic & 1.61 & 3.93 & 1.50 & 13.51 \\
\hline NOBS & 103 & 103 & 103 & 103 \\
\hline
\end{tabular}

- predicted values obtained from table 7 regressions

* indicates significance at $10 \%$ level

** indicates significance at 5\% level

( ) Standard errors appear in parentheses

[ ] p-values appear in brackets 
Table 11a: Technology Adoption and Profitability

\begin{tabular}{cc}
$\begin{array}{c}\text { Number of } \\
\text { Technologies Adopted }\end{array}$ & $\begin{array}{c}\text { Average Profit Margin* } \\
1992\end{array}$ \\
\hline 0 & $3.0 \%(9.7)$ \\
1 & $4.8 \%(7.28)$ \\
2 & $8.5 \%(9.72)$ \\
3 & $8.8 \%(9.72)$ \\
4 & $11.7 \%(6.69)$
\end{tabular}

* Average profit rate is operating profit as a percent of revenue.

Table 11b: Technology Adoption and Leadtime (1992)

Number of

Technologies Adopted

Leadtime (\# days)

$\begin{array}{lc}0 & 172(161) \\ 1 & 117(113) \\ 2 & 109(91) \\ 3 & 91(96) \\ 4 & 66(64)\end{array}$


Table 12: Effect of Technology Adoption on Profitability and Leadtime

\begin{tabular}{|c|c|c|c|c|}
\hline & \multicolumn{2}{|c|}{ Profit Margin } & \multicolumn{2}{c|}{ Leadtime } \\
\hline Variables & base case & + index & base case & + index \\
\hline constant & 4.116 & 1.890 & 120.062 & 146.186 \\
& $(4.557)$ & $(4.347)$ & $(37.506)$ & $(33.942)$ \\
& {$[.196]$} & {$[.336]$} & {$[.002]$} & {$[.000]$} \\
\hline log sales 1992 & 1.329 & .817 & -1.447 & 3.8672 \\
& $(.986)$ & $(1.141)$ & $(9.368)$ & $(9.383)$ \\
& {$[.105]$} & {$[.248]$} & {$[.440]$} & {$[.343]$} \\
\hline \% "basic" & -.025 & -.038 & -.420 & -.282 \\
products & $(.037)$ & $(.039)$ & $(.411)$ & $.438)$ \\
& {$[.253]$} & {$[.179]$} & {$[.163]$} & {$[.267]$} \\
\hline index & & 1.865 & & -20.730 \\
$(1$ if one tech, & & $(1.157)$ & & $(12.669)$ \\
4 if all adopted) & & {$[.0605]$} & & {$[.061]$} \\
\hline F-statistic & 15.66 & 13.20 & 20.05 & 16.51 \\
\hline NOBS & 103 & 103 & 103 & 103 \\
\hline
\end{tabular}

* indicates significance at $10 \%$ level

** indicates significance at $5 \%$ level

( ) standard errors in parenthesis

[ ] P-values in brackets 
Table 13: Combinations of Technologies in 1992

\begin{tabular}{cccc|cc} 
BARCODE & EDI & AUTODIST & TEAM & FREQ & PERCENT \\
\hline 0 & 0 & 0 & 0 & 6 & 5.34 \\
0 & 0 & 0 & 1 & 2 & 1.46 \\
0 & 0 & 1 & 0 & 1 & 0.97 \\
0 & 1 & 0 & 0 & 4 & 3.64 \\
1 & 0 & 0 & 0 & 5 & 5.10 \\
0 & 0 & 1 & 1 & 0 & 0.24 \\
0 & 1 & 0 & 1 & 1 & 0.97 \\
1 & 0 & 0 & 1 & 2 & 1.70 \\
0 & 1 & 1 & 0 & 2 & 2.18 \\
1 & 0 & 1 & 0 & 1 & 0.73 \\
1 & 1 & 0 & 0 & 18 & 17.23 \\
0 & 1 & 1 & 1 & 2 & 1.94 \\
1 & 0 & 1 & 1 & 1 & 1.21 \\
1 & 1 & 0 & 1 & 10 & 9.71 \\
1 & 1 & 1 & 0 & 29 & 28.40 \\
1 & 1 & 1 & 1 & 20 & 19.18 \\
& & & total & 103 & 100
\end{tabular}

1 indicates technology was adopted, 0 means technology was not adopted 


\section{Table 14: Conditional Probability of Sequential Adoption}

a) Probability of Adopting AUTODIST in 1992 conditional on BARCODE and EDI in 1988

AUTODIST 1992

\begin{tabular}{|c|c|c|}
\hline $\begin{array}{c}\text { BARCODE*EDI } \\
1988\end{array}$ & no & yes \\
\hline no & 52.60 & 47.39 \\
\hline yes & 23.05 & 76.95 \\
\hline $\operatorname{lrchi}(1)$ & 7.31 & P-value \\
\hline
\end{tabular}

b) Probability of Adopting TEAM in 1992 conditional on BARCODE and EDI in 1988

TEAM 1992

\begin{tabular}{|c|c|c|}
\hline $\begin{array}{c}\text { BARCODE*EDI } \\
1988\end{array}$ & no & yes \\
\hline no & 69.50 & 30.49 \\
\hline yes & 46.29 & 53.71 \\
\hline
\end{tabular}

Note: $\operatorname{lrchi}(1)=$ chi-squared likelihood ratio test with one degree of freedom which tests Null hypothesis that conditional probabilities are the same betwen the upper and lower rows. P-values are in parentheses. 
Table 15: Evidence of Sequential Adoption

\begin{tabular}{|c|c|c|}
\hline & $\begin{array}{c}\text { AUTODIST } \\
1992^{\circ}\end{array}$ & TEAM92 $^{\circ}$ \\
\hline \multirow{3}{*}{$\begin{array}{c}\text { BARCODE88 } \\
* \text { EDI88 } \\
\text { std error } \\
\text { p-value }\end{array}$} & $2.7400 *$ & $2.1955^{*}$ \\
\hline & 2.6331 & 1.7149 \\
\hline & 0.1556 & 0.1094 \\
\hline \multirow{3}{*}{$\begin{array}{l}\text { Replenishmt } \\
\text { Intensity }\end{array}$} & 0.0297 & 0.0141 \\
\hline & 0.0336 & 0.0277 \\
\hline & 0.1931 & 0.3121 \\
\hline \multirow[t]{3}{*}{ log sales 1992} & 0.9729 & 0.2663 \\
\hline & 0.9778 & 0.8089 \\
\hline & 0.1729 & 0.3776 \\
\hline \multirow{3}{*}{$\begin{array}{l}\text { \% "basic" } \\
\text { products }\end{array}$} & 0.0128 & -0.0129 \\
\hline & 0.0316 & 0.0222 \\
\hline & 0.3432 & 0.2842 \\
\hline \multirow{3}{*}{$\begin{array}{c}\text { non- } \\
\text { proprietary } \\
\text { barcodes } \\
\end{array}$} & -0.5658 & $-2.8824 *$ \\
\hline & 2.8018 & 2.0712 \\
\hline & 0.4209 & 0.0971 \\
\hline \multirow{3}{*}{$\begin{array}{l}\text { POS data } \\
\text { received }\end{array}$} & -0.5595 & $1.7831^{*}$ \\
\hline & 2.0818 & 1.3260 \\
\hline & 0.3944 & 0.0913 \\
\hline \multirow[t]{3}{*}{ ASN provided } & $5.5891 * *$ & 0.9839 \\
\hline & 2.1833 & 1.4327 \\
\hline & 0.0071 & 0.2491 \\
\hline \multirow{3}{*}{$\begin{array}{l}\text { participation of } \\
\text { mfg personnel }\end{array}$} & $1.6318 *$ & 0.3341 \\
\hline & 1.2401 & 0.9661 \\
\hline & 0.0972 & 0.3677 \\
\hline \multirow{3}{*}{$\begin{array}{l}\text { direct labor } \\
\text { costs }\end{array}$} & 0.0122 & 0.0121 \\
\hline & 0.0903 & 0.0534 \\
\hline & 0.4475 & 0.4125 \\
\hline \multirow[t]{3}{*}{ constant } & $-7.3973 *$ & $-8.4497 * *$ \\
\hline & 5.9508 & 2.9296 \\
\hline & 0.1211 & 0.0033 \\
\hline F-statistic & 2.77 & 12.94 \\
\hline Nobs & 103 & 103 \\
\hline
\end{tabular}

* indicates significance at $15 \%$ level

** indicates significance at $5 \%$ level

- Dependent variables are logits of the diffusion values or $\ln \left(\mathrm{y}_{\mathrm{i}} / 1-\mathrm{y}_{\mathrm{i}}\right)$ where $\mathrm{y}_{\mathrm{i}}=\%$ sales involving that particular technology $\mathrm{i}$.

Estimates were obtained using OLS regressions. 
Table 16: Effect of Technology Adoption on Profitability and Leadtime

\begin{tabular}{|c|c|c|c|c|}
\hline & \multicolumn{2}{|c|}{ Profit Margin } & \multicolumn{2}{c|}{ Leadtime } \\
\hline Variables & base case & + indexb & base case & + indexb \\
\hline constant & 4.116 & 4.001 & 120.062 & 123.015 \\
& $(4.557)$ & $(4.792)$ & $(37.506)$ & $(34.980)$ \\
& {$[.196]$} & {$[0.216]$} & {$[.002]$} & {$[0.001]$} \\
\hline log sales 1992 & 1.329 & 0.7459 & -1.447 & 4.7218 \\
& $(.986)$ & $(1.155)$ & $(9.368)$ & $(9.217)$ \\
& {$[.105]$} & {$[0.270]$} & {$[.440]$} & {$[0.308]$} \\
\hline \% "basic" & -.025 & -0.0444 & -.420 & -0.2079 \\
products & $(.037)$ & $(0.039)$ & $(.411)$ & $(0.394)$ \\
& {$[.253]$} & {$[0.136]$} & {$[.163]$} & {$[0.303]$} \\
\hline indexb & & 2.1537 & & -24.0943 \\
3 if 1111 & & $(1.186)$ & & $(10.312)$ \\
2 if 1101 or 1110 & & {$[0.042]$} & & {$[0.010]$} \\
1 if 1100 & & & & \\
0 otherwise & & & & 18.89 \\
\hline F-statistic & 15.66 & 13.11 & 20.05 & 103 \\
\hline Nobs & 103 & 103 & 103 & \\
\hline
\end{tabular}

* indicates significance at $10 \%$ level

** indicates significance at $5 \%$ level

( ) standard errors in parenthesis

[ ] P-values in brackets 


\section{Appendix I: Data Description}

This paper draws on a database of 103 business units in the U.S. apparel industry. The data arises from a comprehensive survey of apparel suppliers that measures various practices and performance outcomes of apparel producers. This includes information on practices in the area of information system, logistics, sourcing, design, manufacturing, supplier relations as well as information about throughput, leadtime, and profitability, and other performance outcomes. Data were collected at the business unit level for 1988 and $1992^{14}$. The sample of apparel manufacturers in our dataset represents approximately one fifth of all shipments of apparel products in the United States in 1992.

The detail and confidential information requested in the sixty-eight page questionnaire meant that a random, stratified sample of the whole apparel industry was not feasible. Instead, in order to secure such detailed responses, the survey effort required sponsorship and support from industry participants.15 This survey research design was particularly successful in assuring response by major manufacturers in the targeted product segments. As a result, the sample is biased toward larger firms and business units.

This study treats missing data explicitly by employing a multiple imputation procedure. In other studies, missing data in surveys forces researchers to choose variables based on availability. The problem with ignoring the missing data and applying complete data statistical techniques to the data is that the hypothesis tests are implemented on different subsamples of the data depending on the variables involved. In contrast, each of our hypothesis tests are

\footnotetext{
${ }^{14}$ A business unit is defined as the lowest level of a firm with responsibilities for the formulation of annual policies dealing with merchandising, planning, manufacturing, distribution, and related activities for a product line or lines, and which collects financial data for those activities. For some organizations, the business unit may be the overall corporation. For others, a number of business units might operate within a single corporate umbrella. A business unit may rely on one (or more) in-house plant(s) to manufacture its products and/or may rely on a network of contractors (with either domestic or foreign operations) to produce its products.

${ }^{15}$ Sponsorship of the survey included one major U.S. department store; one major mass merchandiser, and both of the major clothing unions. The two retail sponsors provided listings of their major suppliers and a crosssection of their smaller suppliers. The clothing unions provided lists of employers under contract with the union in targeted product markets. While the contents of the questionnaire were restricted to the investigators, all survey sponsors provided extensive follow-up support to ensure responses from the targeted industry segments.
} 
performed on the same sample of firms. This multiple imputation approach enables us to obtain the most statistically accurate information from the data set that is possible. Multiple imputation for this data set was performed using Bartlett's Decomposition assuming "missingness at random". We provide an overview of the basic procedure used to generate the imputed data sets and the procedures used to analyze and draw inferences from the multiply imputed data sets in Appendix 2.

\section{Response Rates}

Response rates, based on the procedure described above, varied according to apparel categories. Table A1 provides a breakdown of the number of surveys sent and the response rate by product category. Response rates varied from the $13-17 \%$ in certain women's segments to the mid- $60 \%$ range among pants and jeans manufacturers.

Table A1

\begin{tabular}{|l|c|c|c|}
\hline Category & \# responses & total surveys & response rate \\
\hline Mens Sport & 18 & 51 & $35 \%$ \\
\hline Womens Sport & 16 & 120 & $13 \%$ \\
\hline Intimate Apparel & 12 & 39 & $31 \%$ \\
\hline Tailored & 9 & 45 & $20 \%$ \\
\hline Shirt & 5 & 19 & $26 \%$ \\
\hline Dress & 10 & 79 & $13 \%$ \\
\hline Knit & 17 & 39 & $44 \%$ \\
\hline Pants & 10 & 15 & $67 \%$ \\
\hline Jeans & 6 & 10 & $60 \%$ \\
\hline Men & 51 & 143 & $36 \%$ \\
\hline Women & 47 & 273 & $17 \%$ \\
\hline Children & 5 & 22 & $23 \%$ \\
\hline Home & 7 & 33 & $21 \%$ \\
\hline Other & 20 & 110 & $18 \%$ \\
\hline
\end{tabular}

** Some companies are cross classified, i.e. as both Mens Knits and Womens Knits 
Survey Representativeness

The represenativeness of the sample for selected product groups in terms of 1992 dollar shipments is presented in the following table. Table A2 compares the total value of shipments for specific product groups as reported by the U.S. Department of Commerce to the sum of total sales per product category of survey respondents in the non-imputed data set. The total volue of apparel shipped by business units (not including other textile products) in the sample equals $\$ 13.8$ billion in 1992 . This compares to $\$ 46.4$ billion for the value of total shipments of apparel products in 1991.

Table A2

\begin{tabular}{|c|c|c|c|}
\hline Product Category & $\begin{array}{l}\text { Total \$ Volume } \\
\text { in Sample [a] }\end{array}$ & $\begin{array}{l}\text { Reported \$ } \\
\text { Volume, } \\
\text { Commerce Dept } \\
{[\mathrm{b}]} \\
\end{array}$ & $\begin{array}{l}\text { Sample as \% of } \\
\text { Commerce } \\
\text { Estimate }\end{array}$ \\
\hline & \multicolumn{3}{|c|}{ (1992, Millions of Dollars) } \\
\hline Mens and Womens Jeans & 3,502 & 6,443 & $54 \%$ \\
\hline \multicolumn{4}{|l|}{ Mens Clothing } \\
\hline Suits & 746 & 2,450 & $30 \%$ \\
\hline Slacks & 1,997 & 1,499 & $133 \%$ \\
\hline Dress Shirts & 648 & 1,173 & $55 \%$ \\
\hline \multicolumn{4}{|l|}{ Womens Clothing } \\
\hline Outerwear & 488 & 3,745 & $13 \%$ \\
\hline Dresses & 637 & 5,443 & $12 \%$ \\
\hline Intimate Apparel & 685 & 3,660 & $19 \%$ \\
\hline Blouses & 226 & 3,618 & $6 \%$ \\
\hline Apparel and Other Textile Products & 14,342 & 64,115 & $22 \%$ \\
\hline Mens, Womens, Childrens Apparel [c] & 13,792 & 46,442 & $30 \%$ \\
\hline
\end{tabular}


An alternative method of testing for survey representativesss draws on the U.S. Department of Commerce, Bureau of the Census Longitudinal Research Database (LRD). The LRD data provides detailed annual records of the value of shipments by specific manufacturing establishments. We were able to match 62 business units to the LRD sample in order to compare reported value of shipments of the matched group with overall value of shipment for the appropriate four-digit industry within the entire LRD sample. These results are provided in the Table A3. The matched sample of business units constitute $60 \%$ of our sample of firms, because some business units do not directly manufacture (assemble) goods sold by them. Assuming the same size distribution across matched and unmatched business units, we divide the 1992 percent of total by .6 to obtain a figure of $20 \%$ representation for the whole sample.

\begin{tabular}{|c|c|c|c|c|c|}
\hline \multicolumn{2}{|c|}{ Table A3 } & \multicolumn{2}{|c|}{$\begin{array}{l}\text { Total Value of Shipments } \\
\text { in \$thousands (nominal) }\end{array}$} & \multirow[b]{2}{*}{$\%$ total } & \multirow[b]{2}{*}{ description } \\
\hline year & sic & sample & total & & \\
\hline 1988 & 231 & $\$ 391,495$ & $\$ 3,169,400$ & $12.4 \%$ & men's and boy's suits and coats \\
\hline 1988 & 232 & $\$ 3,077,187$ & $\$ 15,293,800$ & $20.1 \%$ & men's and boy's furnishings \\
\hline 1988 & $233,234,236$ & $\$ 1,037,450$ & $\$ 27,308,600$ & $3.8 \%$ & $\begin{array}{l}\text { women's and children's outerwear } \\
\text { and undergarments }\end{array}$ \\
\hline 1988 & 238,239 & $\$ 101,503$ & $\$ 18,181,600$ & $0.6 \%$ & $\begin{array}{l}\text { miscellaneous, accessories, and } \\
\text { fabricated textile products }\end{array}$ \\
\hline 1988 & total & $\$ 4,607,635$ & $\$ 63,953,400$ & $7.2 \%$ & \\
\hline 1992 & 231 & $\$ 410,247$ & $\$ 2,426,000$ & $16.9 \%$ & men's and boy's suits and coats \\
\hline 1992 & 232 & $\$ 5,312,654$ & $\$ 17,933,900$ & $29.6 \%$ & men's and boy's furnishings \\
\hline 1992 & $233,234,236$ & $\$ 2,102,884$ & $\$ 29,569,800$ & $7.4 \%$ & $\begin{array}{l}\text { women's and children's outerwear } \\
\text { and undergarments }\end{array}$ \\
\hline 1992 & 238,239 & $\$ 424,350$ & $\$ 21,433,100$ & $2.0 \%$ & $\begin{array}{l}\text { miscellaneous, accessories, and } \\
\text { fabricated textile products }\end{array}$ \\
\hline 1992 & total & $\$ 8,250,135$ & $\$ 70,362,800$ & $11.7 \%$ & \\
\hline
\end{tabular}

source: ASM (Annual Survey of Manufacturers) 1988 and 1992 Statistics for Industry Groups and Industries [M88(AS)-1 and M93(AS)-1] and US Census Bureau LRD (Longitudinal Research Database). 
